\title{
New records of philometrids (Nematoda: Philometridae) from marine fishes off Australia, including description of four new species and erection of Digitiphilometroides gen. $\mathbf{n}$.
}

\author{
František Moravec ${ }^{1}$ and Diane P. Barton ${ }^{2}$
}

\begin{abstract}
${ }^{1}$ Institute of Parasitology, Biology Centre of the Czech Academy of Sciences, České Budějovice, Czech Republic;
${ }^{2}$ Department of Primary Industries and Resources, Northern Territory Government, Berrimah, Northern Territory, Australia; Museum and Art Gallery of the Northern Territory, Fannie Bay, Darwin, Northern Territory, Australia
\end{abstract}

\begin{abstract}
The following six species of the Philometridae (Nematoda: Dracunculoidea) were recorded from marine fishes off the northern coast of Australia in 2015 and 2016: Philometra arafurensis sp. n. and Philometra papillicaudata sp. n. from the ovary and the tissue behind the gills, respectively, of the emperor red snapper Lutjanus sebae (Cuvier); Philometra mawsonae sp. n. and Dentiphilometra malabarici sp. n. from the ovary and the tissue behind the gills, respectively, of the Malabar blood snapper Lutjanus malabaricus (Bloch et Schneider); Philometra sp. from the ovary of the goldbanded jobfish Pristipomoides multidens (Day) (Perciformes: all Lutjanidae); and Digitiphilometroides marinus (Moravec et de Buron, 2009) comb. n. from the body cavity of the cobia Rachycentron canadum (Linnaeus) (Perciformes: Rachycentridae). Digitiphilometroides gen. $\mathrm{n}$. is established based on the presence of unique digital cuticular ornamentations on the female body. New gonad-infecting species, $P$. arafurensis and $P$. mawsonae, are characterised mainly by the length of spicules (252-264 $\mu \mathrm{m}$ and 351-435 $\mu \mathrm{m}$, respectively) and the structure of the gubernaculum, whereas P. papillicaudata is characterised mainly by the body length $(70 \mathrm{~mm})$ of gravid female, extent of the oesophageal gland, size of caudal projections and the location in the host. Dentiphilometra malabarici differs from congeners mainly in the arrangement of circumoral teeth (in a single row), extent of the oesophageal gland and the absence of sclerotised teeth or protuberances on the oesophageal lobes in the mouth. Digitiphilometroides marinus has not previously been reported from fishes in Australian waters.
\end{abstract}

Keywords: Dracunculoidea, Philometra, Dentiphilometra, new taxa, Lutjanidae, Rachycentridae

Although recent studies on philometrid nematodes (Philometridae) parasitic in marine and brackish-water fishes in Australian waters have revealed the presence of many new species of these parasites (Moravec and Diggles 2014a,b, 2015, Moravec et al. 2014a, Moravec and Barton $2015,2016)$, the potential fauna of these nematodes within the region is still not known. During helminthological investigations of some marine perciform fishes off the northern Australian coast, philometrids were collected from the ovary of three fish species, Lutjanus malabaricus (Bloch et Schneider), L. sebae (Cuvier) and Pristipomoides multidens (Day) (all Lutjanidae). Each of the two first-named hosts also harboured philometrid females in the tissue behind the gills; a single philometrid female was collected from the body cavity of Rachycentron canadum (Linnaeus) (Rachycentridae).

A close examination revealed that the nematodes from lutjanids included four new species of Philometra Costa, 1845 and Dentiphilometra Moravec et Wang, 2002, whereas the specimen from $R$. canadum is a known species, but for which a new genus should be established. Results of this study are presented herein.

\section{MATERIALS AND METHODS}

Fish were collected by commercial trawlers from several localities off the northern Australia coastline. All fish were anaesthetised, killed and stored in ice for transportation back to the laboratory for further examination. At the laboratory, each fish was measured (total length; mm); the gills, mouth cavity and associated tissues, and the viscera were removed, placed in a sealed plastic bag and frozen until examined for parasites. At this time, the gill arches were separated, the tissues dorsal to the mouth cavity gently teased apart and the body cavity opened prior to examination for parasites under the dissecting microscope.

The nematodes obtained were washed in physiological saline and then fixed and preserved in $70 \%$ ethanol. For light microscopical examination, the nematodes were cleared using glycerine. Drawings were made with the aid of a Zeiss drawing attachment. Specimens used for scanning electron microscopy (SEM) were postfixed in $1 \%$ osmium tetroxide (in phosphate buffer), de- 
hydrated through a graded acetone series, critical-point-dried and sputter-coated with gold; they were examined using a JEOL JSM$7401 \mathrm{~F}$ scanning electron microscope at an accelerating voltage of $4 \mathrm{kV}$ (GB low mode). All measurements are in micrometres unless otherwise indicated. The fish nomenclature adopted follows FishBase (Froese and Pauly 2017). Type and voucher nematode specimens are deposited in the South Australian Museum, Adelaide, Australia (SAM) and in the Helminthological Collection of the Institute of Parasitology, Biology Centre of the Czech Academy of Sciences, České Budějovice, Czech Republic (IPCAS).

\section{RESULTS}

Philometridae Baylis et Daubney, 1926

Philometra arafurensis sp. n.

Figs. 1, 2

ZooBank number for species:

urn:lsid:zoobank.org:act:0985A412-C839-4C67-9662-D3F5038803D2

Description of male (4 specimens; measurements of holotype in parentheses). Body whitish, filiform, tapering at both ends, 3.71-4.49 $\mathrm{mm}$ (4.49 $\mathrm{mm}$ ) long, maximum width at middle 66-81 (69); anterior part of body somewhat narrowed just posterior to cephalic end (Figs. 1D, 2E); body width at this narrowed part 24-30 (30). Maximum width/body length ratio 1 : 50-65 (1: 65); width of cephalic end 30-36 (36), that of posterior end 33-36 (36). Cuticle smooth. Cephalic end rounded. Oral aperture small, oval, surrounded by 14 cephalic papillae arranged in 2 circles: external circle formed by 4 submedian pairs of papillae; internal circle formed by 4 submedian and 2 lateral papillae (Figs. 1J, 2A). Small lateral amphids just posterior to lateral papillae of internal circle in dorsoventral view (Figs. 1J, 2A). Oesophagus 372-539 (539) long, maximum width 21-24 (23), with slightly inflated anterior end; anterior inflation 33-36 (36) long and 15 (15) wide; posterior part of muscular oesophagus overlapped by well-developed oesophageal gland with large cell nucleus in middle (Fig. 1D). Nerve ring, excretory pore and oesophageal nucleus 149-198 (174), 156-225 (207) and 267-381, respectively, from anterior extremity (Figs. 1D, 2G). Testis reaches anteriorly to short distance posterior to nerve ring. Posterior end of body blunt, with broad U-shaped caudal mound situated laterally and dorsally to cloacal aperture; dorsal part of caudal mound with longitudinal line of slightly elevated cuticle in middle (Figs. 1P, 2D). Four pairs of very flat, indistinct caudal papillae close to each other situated on sides of cloacal aperture on mound and pair of large papillae located posteriorly to cloaca outside mound (Figs. 1P, 2D). Phasmids not located. Spicules needle-like, equal or slightly subequal, with moderately expanded proximal and sharply pointed distal ends (Figs. 1E,F, 2C,H); length of spicules 252-264 (252), representing 6-7\% (6\%) of body length. Gubernaculum 129-147 (129) long, with anterior portion somewhat dorsally bent; length of anterior bent part 33-39 (39), representing 24-30\% (30\%) of entire gubernaculum length (Fig. 1F,G); distal end of gubernacu- lum with slightly outlined low, elongate protuberance and numerous dorsolateral transverse lamella-like structures; dorsal protuberance on gubernaculum appears single in lateral view (Figs. 1F,G,L, 2C,H) but, in fact, it consists of two dorsolateral lamellar parts separated from each other by smooth, somewhat depressed longitudinal field when observed dorsally (Figs. 1K, 2F); distal end of gubernaculum rounded in dorsal view (Figs. $1 \mathrm{~K}, 2 \mathrm{~F}$ ) and with 2 ventral longitudinal grooves (Fig. 2C). Length ratio of gubernaculum and spicules $1: 1.80-2.02$ ( $1: 1.95)$. Spicules and gubernaculum well sclerotised, yellowish, their proximal ends colourless.

Gravid female (1 complete [allotype] and 1 incomplete larvigerous specimen; measurements of paratype in parentheses). Body of fixed specimens brown, with distinct dark-brown intestine visible through cuticle, ends rounded. Posterior part of body somewhat narrower than anterior part; maximum width in region just posterior to oesophagus. Cuticle smooth. Body length $220 \mathrm{~mm}$, maximum width 816 (884); maximum width/body length ratio $1: 270$. Width of cephalic end 272 (422). Cephalic papillae small, indistinct when viewed laterally (Fig. 1A). Oral aperture oval, surrounded by small cephalic papillae arranged in 2 circles: inner circle consisting of 4 submedian and 2 lateral single papillae, outer circle formed by 4 submedian pairs of papillae; each pair of outer submedian papillae consisting of 1 circular and 1 elongate papilla; lateral amphids slightly outlined (Figs. 1I, 2B). Length of oesophagus including distinct anterior bulbous inflation $1.39 \mathrm{~mm}(1.29 \mathrm{~mm})$ long, $0.6 \%$ of body length; maximum width of posterior part of oesophagus including gland 150 (150); anterior oesophagus inflation 163 (150) long, 150 (136) wide. Oesophageal gland well developed, opening into oesophagus just posterior to nerve ring, with large cell nucleus in middle. Nerve ring and oesophageal nucleus 394 (381) and 952, respectively, from anterior extremity. Ventriculus small, 41 (41) long, 122 (122) wide. Posterior end of intestine attached by ligament to body wall near caudal end (Fig. 1M); length of ligament $1.09 \mathrm{~mm}$. Vulva and anus absent. Ovaries reflexed near body extremities. Uterus occupies most space of body, filled with numerous eggs and larvae (Fig. 1A,M). Larvae $(\mathrm{n}=5$ ) 531-582 long and 15-18 wide; oesophagus 159-174 long, comprising 30-31\% of body length; length of sharply pointed tail 150-174, comprising $28-30 \%$ of body length (Fig. 1H). Posterior end of female rounded, 394 wide, with 2 very small lateral papilla-like caudal projections (Fig. 1M-O).

Subgravid female (body fragments of 3 ovigerous specimens). Largest body fragment $145 \mathrm{~mm}$ long; maximum width of body 653-721. Width of cephalic end 204. Cephalic papillae small, indistinct when viewed laterally (Fig. 1B). Number and arrangement of cephalic papillae and amphids as in gravid specimens. Oesophagus including anterior inflation $1.16 \mathrm{~mm}$ long; maximum width of posterior part of oesophagus including gland 136; anterior oesophagus inflation 136-163 long and 136 wide. Nerve ring and oesophageal nucleus 299 and 544, respectively, from anterior extremity. Ventriculus 41 long, 109 wide. 


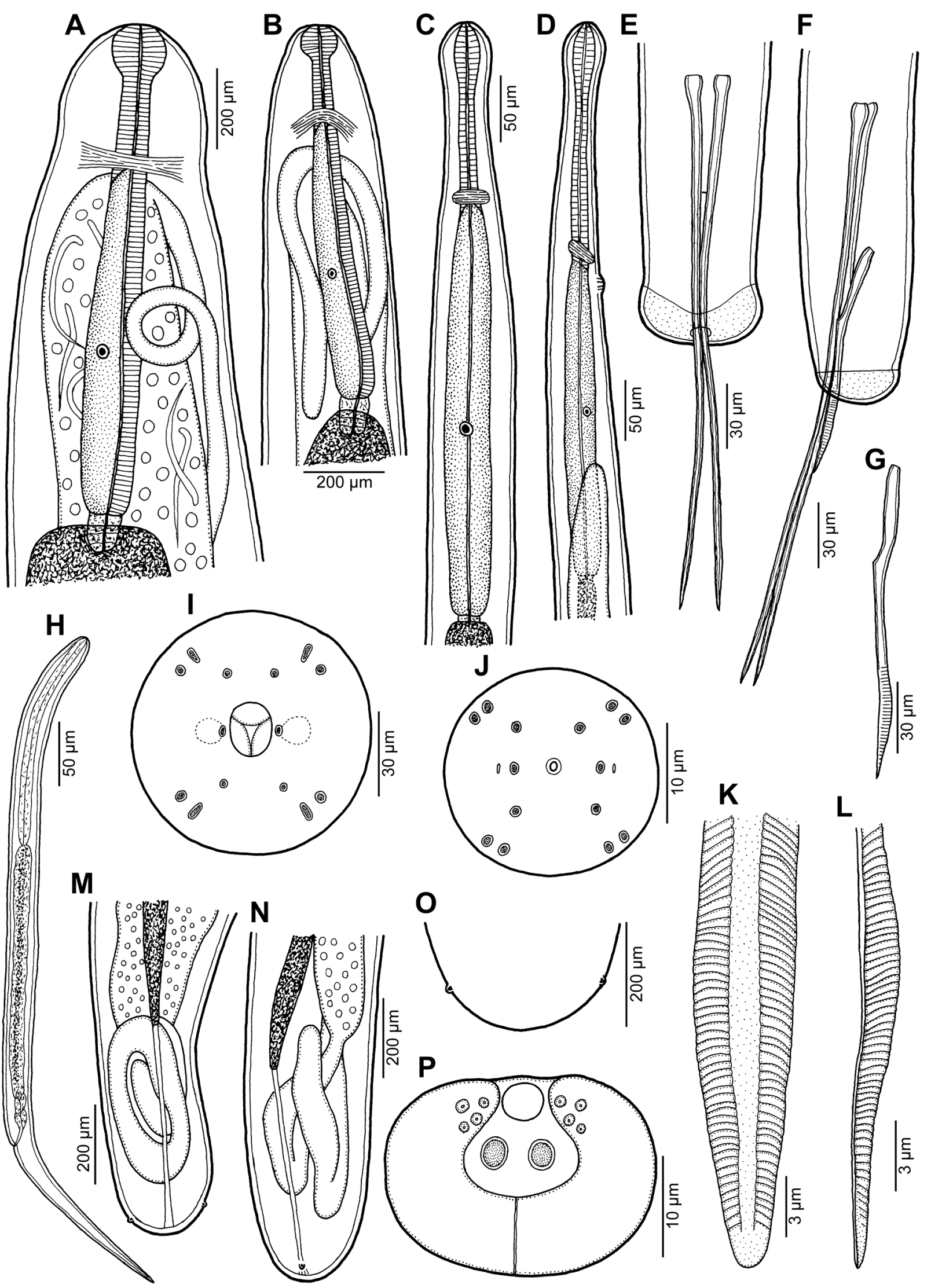

Fig. 1. Philometra arafurensis sp. n. from the ovary of Lutjanus sebae (Cuvier). A, B - anterior end of gravid and subgravid female, respectively, lateral views; $\mathbf{C}, \mathbf{D}$ - anterior end of nongravid female and male, respectively, lateral views; $\mathbf{E}, \mathbf{F}$ - posterior end of male, ventral and lateral views, respectively; $\mathbf{G}$ - gubernaculum, lateral view; $\mathbf{H}$ - larva from uterus; $\mathbf{I}, \mathbf{J}$ - cephalic end of female and male, respectively, apical views; $\mathbf{K}, \mathbf{L}$ - distal portion of gubernaculum, dorsal and lateral views, respectively; $\mathbf{M}$ - posterior end of gravid female, dorsal view; $\mathbf{N}$ - posterior end of subgravid female, lateral view; $\mathbf{O}$ - caudal projections on posterior end of gravid female, dorsal view; $\mathbf{P}$ - caudal end of male, apical view. 

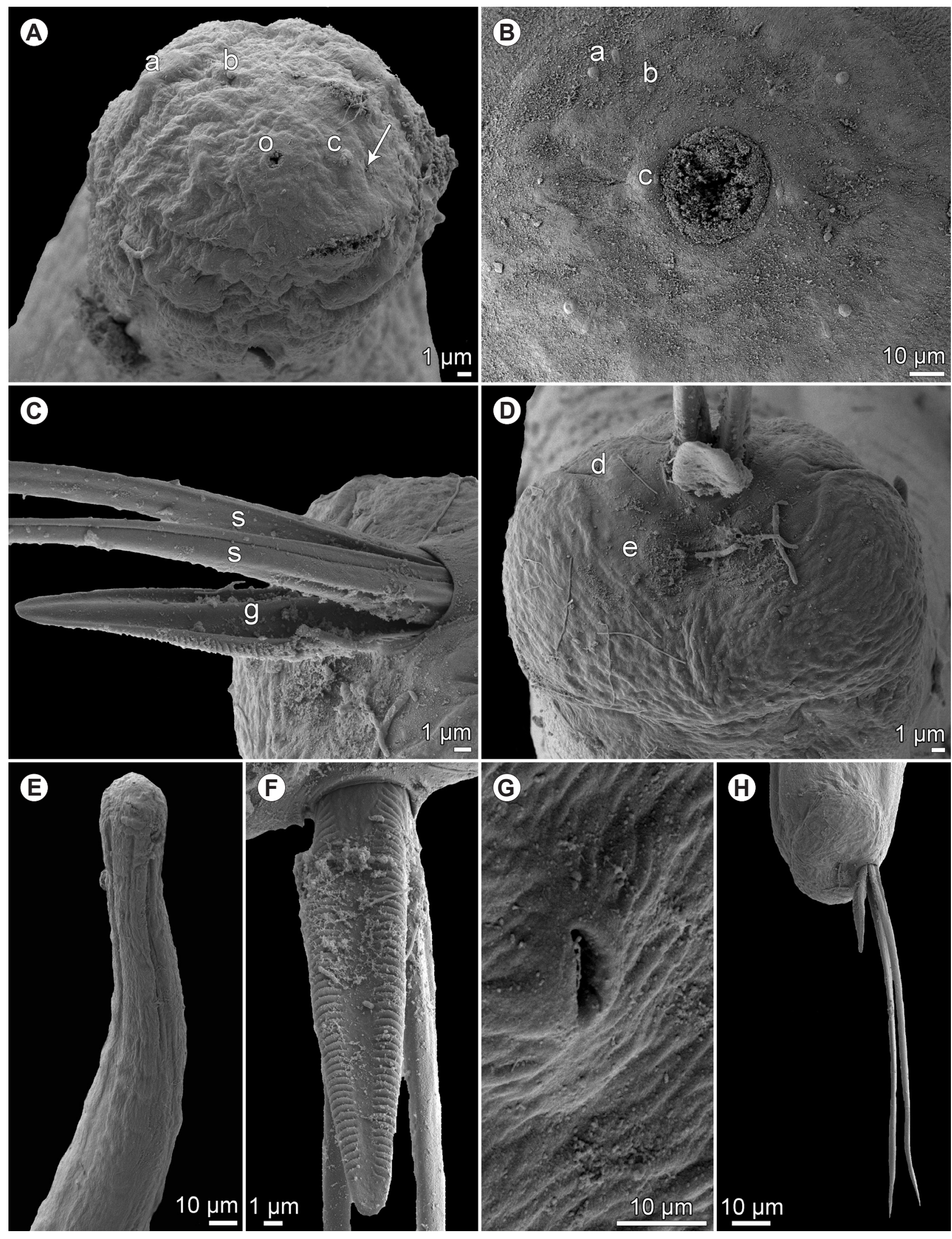

Fig. 2. Philometra arafurensis sp. n. from the ovary of Lutjanus sebae (Cuvier), scanning electron micrographs. $\mathbf{A}-$ cephalic end of male, subapical view (arrow indicates amphid); B - cephalic end of gravid female, apical view; $\mathbf{C}$ - distal end of gubernaculum, sublateral view (note two ventral longitudinal grooves); D - caudal end of male, subterminal view; $\mathbf{E}$ - anterior end of male, lateral view; $\mathbf{F}$ - distal end of gubernaculum, dorsal view; $\mathbf{G}$ - excretory pore; $\mathbf{H}$ - posterior end of male with extruded spicules and gubernaculum (lateral view). Abbreviations: a - submedian pair of cephalic papillae of external circle; $b$ - submedian cephalic papilla of internal circle; $\mathrm{c}$ - lateral cephalic papilla of internal circle; $\mathrm{d}$ - group of four adanal papillae; $\mathrm{e}$ - large postcloacal papilla; $\mathrm{g}$ - gubernaculum; $\mathrm{o}-$ oral aperture; $\mathrm{s}-$ spicule. 
Length of intestinal ligament 544-1,088. Vulva and anus absent. Uterus filled with numerous eggs. Posterior end rounded, 272 wide, without any caudal projections.

Nongravid female ( 8 mature specimens with empty uterus). Body length 4.07-11.76 mm, maximum width 81-186; maximum width/body length ratio 1 : 50-63. Width of cephalic end 39-78. Cephalic structures as in gravid specimens. Oesophagus, with slightly outlined inflation at anterior end, 423-768 long, 7-12\% of body length (Fig. 1C); maximum width of posterior part of oesophagus including gland 30-54. Nerve ring and oesophageal nucleus 147-210 and 279-546, respectively, from anterior extremity. Length of intestinal ligament 27-126. Uterus empty. Caudal end rounded, 39-93 wide, without caudal projections.

Type host: Emperor red snapper, Lutjanus sebae (Cuvier) (Perciformes: Lutjanidae).

Site of infection: Ovary.

Type locality: Arafura Sea East, off northern Australia (collected 3 February 2016).

Other localities: Joseph Bonaparte Gulf (collected 3 August 2015) and Timor Reef Fishery (collected 18 October 2015), all off northern Australia.

Total prevalence and intensity: 11\% (13 fish infected/120 fish examined), $28 \%$ (13/47) in female fish only; 1-4 (mean 2) nematodes per fish.

Deposition of type specimens: SAM Cat. Nos. AHC 48205 (holotype) and AHC 48206 (allotype); IPCAS Cat. No. $\mathrm{N}-1148)$ (paratypes).

Etymology: The scientific name arafurensis proposed for this nematode relates to the type locality of this species, i.e. the Arafura Sea.

Remarks. Gonad-infecting philometrids are known to exhibit a high degree of host specificity, with each of the species of congeneric fish definitive hosts usually harbouring only one morphologically well-distinguished species of Philometra (see e.g. Moravec et al. 2014b, 2016). Therefore, only species of Philometra parasitising fishes of the family Lutjanidae are considered for the comparison with the new species.

To date, the following eight gonad-infecting species of Philometra have been described from lutjanid hosts: P. argentimaculati Moravec et Manoharan, 2014 from Lutjanus argentimaculatus (Forsskål) in the Bay of Bengal; P. brevicollis Moravec et Justine, 2011 from Lutjanus vitta (Quoy et Gaimard) from off New Caledonia; P. carponotati Moravec et Diggles, 2014 from Lutjanus carponotatus (Richardson) off Australia; P. fulvi Moravec et Manoharan, 2014 from Lutjanus fulvus (Foerster) in the Bay of Bengal; P. latispicula Moravec, Bakenhaster et Fajer-Ávila, 2014 from Lutjanus griseus (Linnaeus) in the Gulf of Mexico; P. longispicula Moravec, Bakenhaster et Fajer-Ávila, 2014 from Lutjanus campechanus (Poey) and L. vivanus $(\mathrm{Cu}-$ vier) in the Gulf of Mexico; P. mira Moravec et Justine, 2011 from Lutjanus vitta from off New Caledonia; and P. synagridis Moravec, Bakenhaster et Fajer-Ávila, 2014 from Lutjanus synagris (Linnaeus) in the Gulf of Mexico
(Moravec and Justine 2011, Moravec and Diggles 2014a, Moravec and Manoharan 2014, Moravec et al. 2014b).

Based on the length of spicules, only $P$. carponotati (spicules 225-252 $\mu \mathrm{m}$ vs 252-264 $\mu \mathrm{m}$ long), P. argentimaculati $(219-228 \mu \mathrm{m})$ and $P$. brevicollis $(279-312 \mu \mathrm{m})$ resemble $P$. arafurensis sp. n., whereas the spicules of other species are either shorter $(<219 \mu \mathrm{m})(P$. fulvi, P. latispicula, $P$. mira and $P$. synagridis) or distinctly longer $(>378 \mu \mathrm{m})$ (P. longispicula). However, the males of $P$. argentomaculati are smaller (body length 2.56-3.07 $\mathrm{mm} v \mathrm{~s}$ $3.71-4.49 \mathrm{~mm}$ ), their spicules and the gubernaculum are somewhat shorter (length of gubernaculum 90-120 $\mu \mathrm{m}$ vs 129-147 $\mu \mathrm{m}$ ), postcloacal papillae are absent ( $v s$ present) and the maximum body width/length ratio of gravid females is different ( 1 : 165-192 vs 1 : 270). Males of $P$. brevicollis are longer (body length 5.39-5.92 $\mathrm{mm} v \mathrm{~s}$ 3.71-4.49 $\mathrm{mm}$ ), spicules and the gubernaculum are longer (length of gubernaculum 151-168 $\mu \mathrm{m} v s$ 129-147 $\mu \mathrm{m}$ ), postcloacal papillae are absent ( $v s$ present) and the relative length of spicules to the body length is smaller $(5 \%$ vs $6-7 \%$ ).

Based on the length of spicules, male caudal structures and the shape and structure of the distal portion of the gubernaculum, the new species is most similar to $P$. carponotati, a species also reported from Australian waters. However, the latter has somewhat shorter spicules and gubernaculum (length of gubernaculum 99-117 $\mu \mathrm{m} v \mathrm{~s}$ 129-147 $\mu \mathrm{m}$ ), the proximal, curved portion of the gubernaculum represents $30-40 \%$ (vs 24-30\%) of the total gubernaculum length, submedian pairs of external cephalic papillae of females are distinctly elevated and formed by two circular papillae ( $v s$ not elevated, formed by one circular and one elongate papilla), the body of gravid female is much shorter (72 $\mathrm{mm}$ vs $220 \mathrm{~mm}$ ), the maximum body width/length ratio of the gravid female is $1: 100$ (vs 1 : 270 ) and the length of oesophagus represents $1.6 \%$ (vs $0.6 \%$ ) of the entire body length, and larvae from the uterus are somewhat shorter (477-543 $\mu \mathrm{m}$ vs 531-583 $\mu \mathrm{m})$. Therefore, the present specimens from L. sebae are considered to represent a new species.

Philometra mawsonae sp. n.

Figs. 3-5

ZooBank number for species:

urn:1sid:zoobank.org:act:A80DA0C9-D7D1-4C90-B960-5360389A8C74

Description of male (13 specimens; measurements of holotype in parentheses). Body whitish, filiform, tapering at both ends, 3.45-4.34 $\mathrm{mm}(4.34 \mathrm{~mm})$ long, maximum width at middle 51-60 (60); anterior part of body somewhat narrowed just posterior to cephalic end (Figs. 3C, $4 \mathrm{G}$ ); body width at this narrowed part 21-27 (24). Maximum width/body length ratio $1: 63-75$ (1: 72); width of cephalic end 24-30 (27), that of posterior end 30-36 (33). Cuticle smooth. Cephalic end rounded. Oral aperture small, triangular, surrounded by 14 cephalic papillae arranged in 2 circles: external circle formed by 4 submedian pairs of papillae; internal circle formed by 4 submedian 

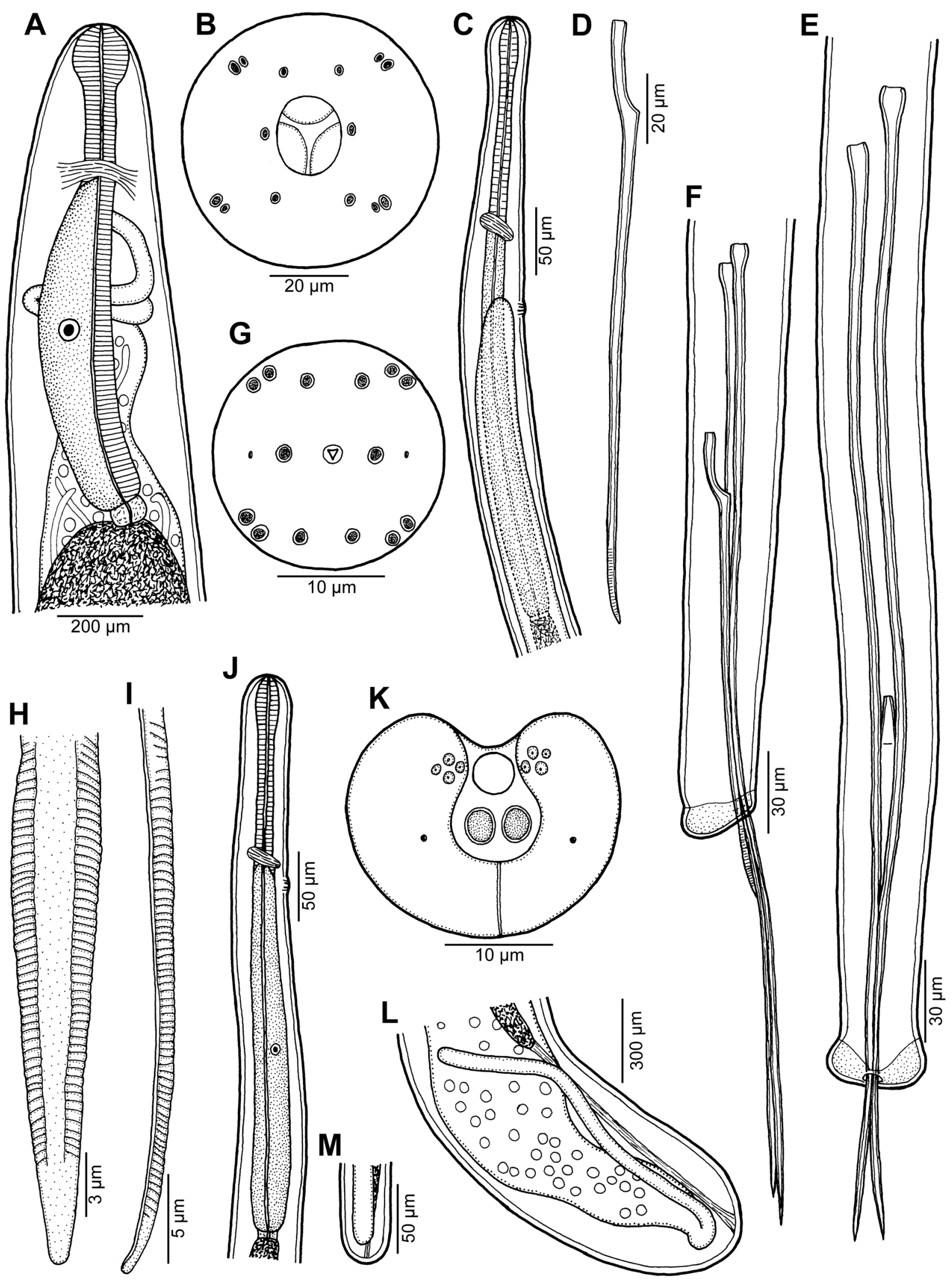

Fig. 3. Philometra mawsonae sp. $n$. from the ovary of Lutjanus malabaricus (Bloch et Schneider). A - anterior end of gravid female, lateral view; B - cephalic end of gravid female, apical view; C - anterior end of male, lateral view; D - gubernaculum, lateral view; E, $\mathbf{F}$ - posterior end of male, lateral and ventral views, respectively; $\mathbf{G}$ - cephalic end of male, apical view; $\mathbf{H}$, I - distal part of gubernaculum, dorsal and lateral views, respectively; $\mathbf{J}$ - anterior end of nongravid female, lateral view; $\mathbf{K}$ - caudal end of male, apical view; $\mathbf{L}$ - posterior end of gravid female, lateral view; $\mathbf{M}$ - posterior end of nongravid female, lateral view. 


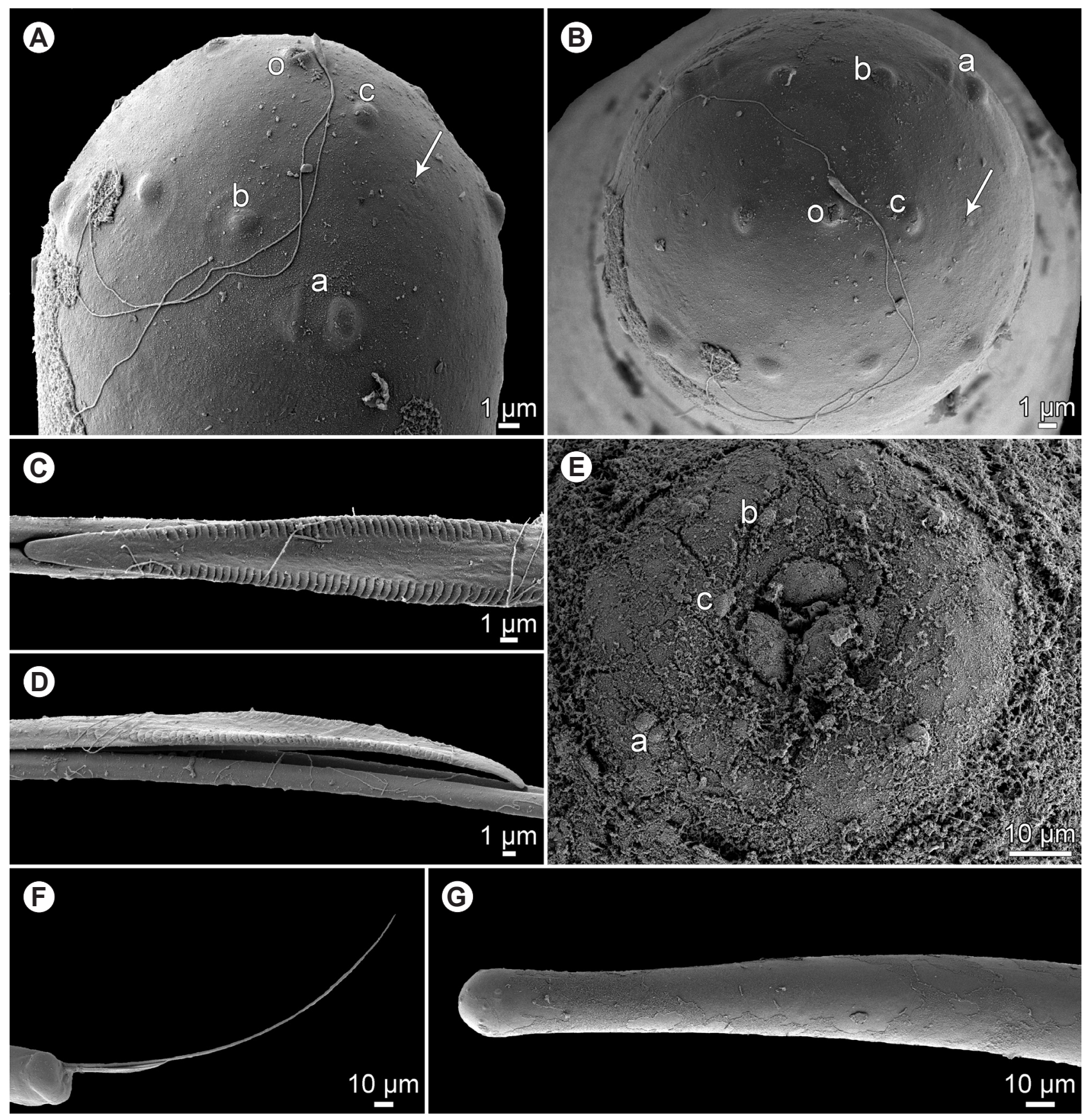

Fig. 4. Philometra mawsonae sp. n. from the ovary of Lutjanus malabaricus (Bloch et Schneider), scanning electron micrographs. A, $\mathbf{B}$ - cephalic end of male, sublateral and apical views, respectively (arrow indicates amphid); C, D - distal portion of gubernaculum, dorsal and lateral views, respectively; $\mathbf{E}$ - cephalic end of gravid female, apical view; $\mathbf{F}$ - posterior end of male with extruded spicules and gubernaculum, lateral view; $\mathbf{G}$ - anterior end of male; Abbreviations: a - submedian pair of cephalic papillae of external circle; $\mathrm{b}$ - submedian cephalic papilla of internal circle; $\mathrm{c}$ - lateral cephalic papilla of internal circle; $\mathrm{o}$ - oral aperture.

and 2 lateral papillae (Figs. 3G, 4A,B). Small lateral amphids just posterior to lateral papillae of internal circle in dorsoventral view (Figs. 3G, 4A,B). Oesophagus 405-546 (408) long, maximum width 15-21 (15), with slightly inflated anterior end; anterior inflation 27-33 (33) long and 9-15 (15) wide; posterior part of muscular oesophagus overlapped by well-developed oesophageal gland with large cell nucleus in middle (Fig. 3C). Nerve ring, excretory pore and oesophageal nucleus 147-171 (171), 180-201 (195) and 300-357 (303), respectively, from anterior extremity (Fig. 3C). Testis reaches anteriorly to short dis- tance posterior to nerve ring. Posterior end of body blunt, with broad U-shaped caudal mound situated laterally and dorsally to cloacal aperture; dorsal part of caudal mound with longitudinal line of slightly elevated cuticle in middle (Figs. 3K, 5A-C). Four pairs of very flat, indistinct caudal papillae close to each other situated on sides of cloacal aperture on mound and pair of large papillae located posteriorly to cloaca outside mound (Figs. 3K, 5A-C). Phasmids small, located on caudal mound at level of dorsal border of postcloacal papillae. Spicules needle-like, slightly unequal in length, with moderately expanded proximal and sharply 

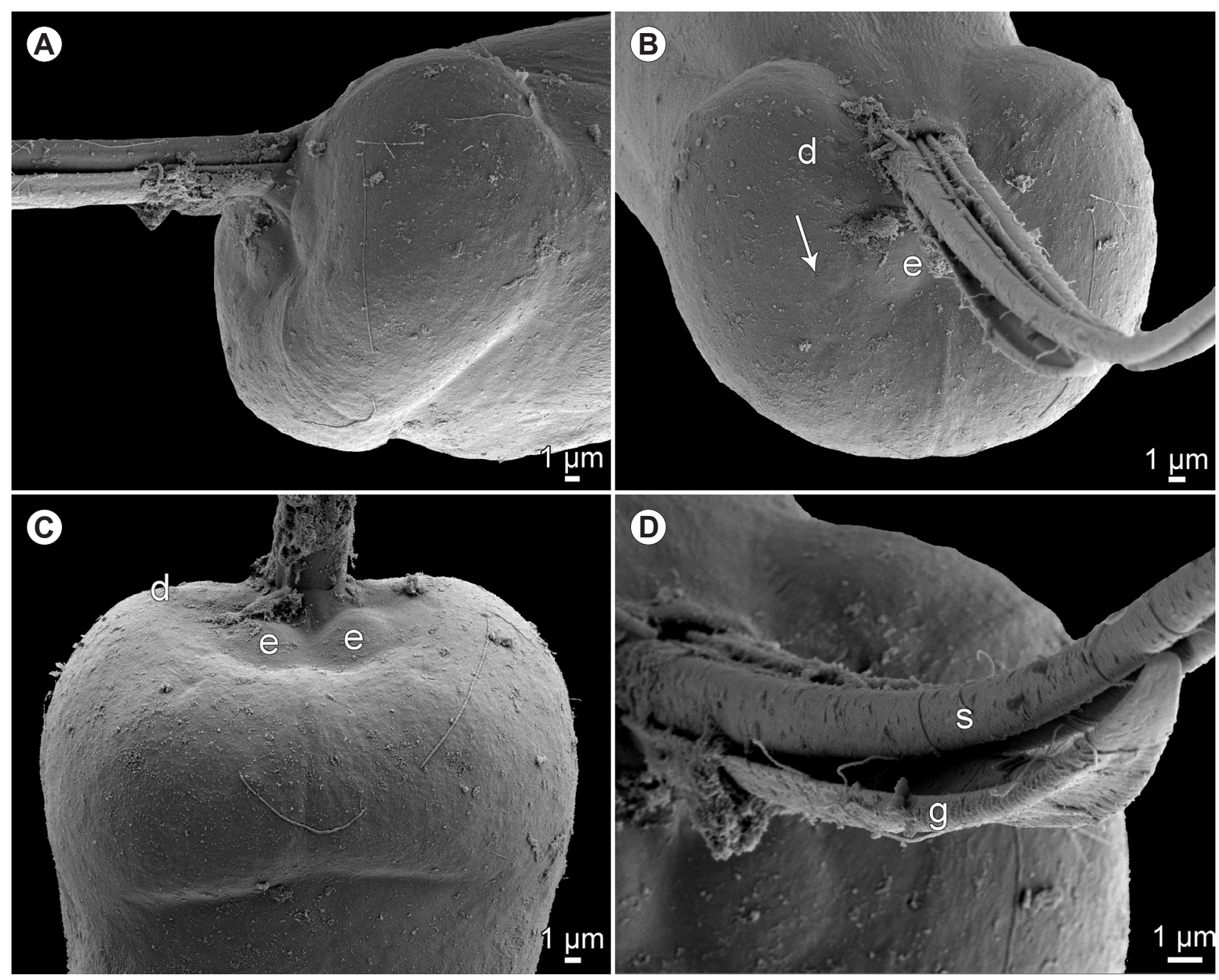

Fig. 5. Philometra mawsonae sp. n. from the ovary of Lutjanus malabaricus (Bloch et Schneider), scanning electron micrographs of male. A-C - caudal end, lateral, apical and dorsal views, respectively (arrow indicates phasmid); $\mathbf{D}$ - distal portion of gubernaculum, sublateral view (note ventral longitudinal grooves). Abbreviations: $\mathrm{d}$ - group of four adanal papillae; $\mathrm{e}$ - large postcloacal papilla; $\mathrm{g}-$ gubernaculum; s-spicule.

pointed distal ends (Figs. 3E,F, 4F); right spicule 384-435 (432) long, length of left spicule 351-420 (420); length ratio of spicules $1: 1.02-1.09$; larger spicule represents $10-11 \%$ (10\%) of body length. Gubernaculum 174-195 (180) long, with proximal portion somewhat dorsally bent; length of anterior bent part 21-33 (21), representing 12-17\% (12\%) of entire gubernaculum length (Fig. 3D,E); distal portion of gubernaculum without dorsal protuberance in lateral view (Figs. 3I, 4D, 5D), but with numerous transverse lamella-like structures; two dorsolateral lamellar parts separated from each other by smooth, somewhat depressed longitudinal field when observed dorsally (Figs. 3H, 4C); distal end of gubernaculum rounded in dorsal view (Figs. 3H, 4C); 2 ventral longitudinal grooves present (Fig. 5B,D). Length ratio of gubernaculum and larger spicule 1 : 2.06-2.40 (1 : 2.40). Spicules and gubernaculum well sclerotised, yellowish, their proximal ends colourless.

Gravid female (3 larvigerous specimens; measurements of allotype in parentheses). Body of fixed specimens brown, with distinct dark-brown intestine visible through cuticle, ends rounded. Posterior part of body somewhat narrower than anterior part; maximum width in region just posterior to oesophagus. Cuticle smooth. Body length 70-111 mm (111 mm), maximum width 775-979 (979); maximum width/body length ratio $1: 84-113$ (1: 113). Width of cephalic end 150-231 (150). Cephalic papillae small, indistinct when viewed laterally (Fig. 3A). Oral aperture oval, surrounded by small cephalic papillae arranged in 2 circles; inner circle consisting of 4 submedian and 2 lateral single papillae, outer circle formed by 4 submedian pairs of papillae (Figs. 3B, 4E). Oesophagus including distinct anterior bulbous inflation $1.20-1.43 \mathrm{~mm}(1.43 \mathrm{~mm})$ long, $1.6-1.8 \%$ (1.3\%) of body length; maximum width of posterior part of oesophagus including gland 177-204 (177); anterior oesophageal inflation 109-122 (109) long, 122-150 (122) wide. Oesophageal gland well developed, opening into oesophagus just posterior to nerve ring, with large cell nucleus in middle. Nerve ring and oesophageal nucleus 299-340 (313) and 734-816 (816), respectively, from anterior extremity. Ventriculus small, 27-54 (27) long, 82-122 (82) wide. Posterior end of intestine attached by ligament to body wall near caudal end (Fig. 3L); length 
of ligament 449-1,115 (1,115). Vulva and anus absent. Ovaries reflexed near body extremities. Uterus occupies most space of body, filled with numerous eggs and larvae (Fig. 3A,L). Larvae $(n=5)$ 513-585 long and 18 wide; oesophagus 150-174 long, comprising 27-34\% of body length; length of tail 141-165, comprising $27-31 \%$ of body length. Posterior end of female rounded, 204-544 (544) wide, without caudal projections (Fig. 3L).

Subgravid female (1 ovigerous specimen). Body length $48 \mathrm{~mm}$, maximum body width 530; maximum body width/ length ratio $1: 1.91$. Width of cephalic end 150 . Number and arrangement of cephalic papillae as in gravid specimens. Oesophagus including anterior inflation $1.02 \mathrm{~mm}$ long; maximum width of posterior part of oesophagus including gland 150; anterior oesophagus inflation 95 long and 109 wide. Nerve ring and oesophageal nucleus 286 and 721, respectively, from anterior extremity. Ventriculus 54 long, 82 wide. Length of intestinal ligament 245. Vulva and anus absent. Uterus filled with numerous eggs. Posterior end rounded, 163 wide, without caudal projections.

Nongravid female (1 mature specimen with empty uterus). Body length $2.92 \mathrm{~mm}$, maximum width 78; maximum width/body length ratio $1: 37$. Width of cephalic end 30. Cephalic structures as in gravid specimens. Oesophagus with slightly outlined inflation at anterior end 423 long, 15\% of body length (Fig. 3J); maximum width of posterior part of oesophagus including gland 15 . Nerve ring, excretory pore and oesophageal nucleus 138, 156 and 270 , respectively, from anterior extremity. Uterus empty. Caudal end rounded, 30 wide, without caudal projections (Fig. 3M).

Type host: Malabar blood snapper, Lutjanus malabaricus (Bloch et Schneider) (Perciformes: Lutjanidae).

Site of infection: Ovary.

Type locality: Arafura Sea East, off northern Australia (collected 14 August 2015).

Other localities: Joseph Bonaparte Gulf (collected 3 August 2015), Gulf of Carpentaria (collected 21 August 2015), Arafura Sea West (collected 22 April 2016) and Timor Reef Fishery (collected 28 October 2016), all off northern Australia.

Total prevalence and intensity: 26\% (36 fish infected/139 fish examined), $39 \%$ (36/93) in female fish only; 1-136 (mean 9) nematodes per fish.

Deposition of type specimens: SAM Cat. Nos. AHC 48207 (holotype) and AHC 48208 (allotype); IPCAS Cat. No. N-1149 (paratypes).

Etymology: This species is named in honour of late Patricia M. Thomas-Mawson for her pioneering work on fish nematodes in Australia.

Remarks. Of the gonad-infecting species of Philometra so far described from lutjanid fishes (see above), $P$. mawsonae sp. n. resembles only P. longispicula in the length of spicules (510-690 $\mu \mathrm{m}$ in P. longispicula from its type host $v s$ 351-435 $\mu \mathrm{m}$ in the new species) and in that the spicules are unequal. However, P. longispicula has a much shorter gubernaculum (99-129 $\mu \mathrm{m} v s$ 174-195 $\mu \mathrm{m})$ with the relatively longer curved proximal portion $(22-33 \% \mathrm{vs}$ $12-17 \%$ of the total gubernaculum length), the greater rela- tive length of the larger spicule to the body length (13-19\% vs 10-11\%), a different gubernaculum/larger spicule length ratio (1: 4.70-6.90 vs $1: 2.06-2.40)$, much longer gravid females (130-250 mm vs 70-111 mm), female caudal projections present ( $v s$ absent) and different dorsal lamellar structures on the distal end of the gubernaculum (tip dorsally with several transverse lamellate structures $v s$ tip dorsally smooth, without such lamellae). Moreover, both species occur in distant geographical regions (Gulf of Mexico $v s$ off northern Australia).

Moravec et al. (2014b) also assigned to P. longispicula two philometrid males found in the gonad of the silk snapper Lutjanus vivanus from the Gulf of Mexico, noted for somewhat shorter spicules (459-519 $\mu \mathrm{m}$ and 378-459 $\mu \mathrm{m}$ long) as compared to those of $P$. longispicula specimens from the type host. However, considering the high degree of host specificity in gonad-infecting species of Philometra and the fact that the specimens from $L$. vivanus were not studied by SEM, it is possible that these belong to a different, hitherto undescribed species.

Philometra papillicaudata $\mathrm{sp} . \mathrm{n}$.

Figs. 6, 7

ZooBank number for species:

urn:Isid:zoobank.org:act:1C2E1F99-04C3-4E70-B70D-E22A000AEF7A

Description of gravid female (1 complete larvigerous specimen, holotype; measurements of 4 incomplete paratype specimens in parentheses). Body of fixed specimens white-yellow, with light-brown intestine visible through cuticle, ends rounded. Cuticle smooth. Body length $70 \mathrm{~mm}$, maximum width $1.29 \mathrm{~mm}(1.17-1.31 \mathrm{~mm})$; maximum width/body length ratio $1: 54$. Width of cephalic end 272 (299-340). Cephalic papillae small, indistinct when viewed laterally (Fig. 6A,B). Oral aperture oval, surrounded by small cephalic papillae arranged in 2 circles; inner circle consisting of 4 submedian and 2 lateral single papillae, outer circle formed by 4 submedian pairs of papillae (Figs. 6C, 7A-D). Oesophagus including distinct anterior bulbous inflation $1.90 \mathrm{~mm}(2.04-2.23 \mathrm{~mm})$ long, 3\% of body length; maximum width of posterior part of oesophagus including gland 95 (109); anterior oesophagus inflation 109 (109-136) long, 122 (122-136) wide. Oesophageal gland well developed, opening into oesophagus just posterior to nerve ring, with large cell nucleus in middle (Fig. 6A). Nerve ring and oesophageal nucleus 286 (245-272) and $1.01 \mathrm{~mm}$ $(1.36 \mathrm{~mm})$, respectively, from anterior extremity. Ventriculus small, 27 (41) long, 68 (95) wide. Posterior end of intestine attached by ligament to body wall near caudal end (Fig. $6 \mathrm{E}$ ); length of ligament $1.09 \mathrm{~mm}$. Vulva and anus absent. Ovaries reflexed near body extremities (Fig. 6A,E). Uterus occupies most space of body, filled with numerous eggs and larvae (Fig. 6A,E). Larvae $(\mathrm{n}=5)$ 480-522 long and 15-18 wide; oesophagus 162-198 long, comprising $32-39 \%$ of body length; length of tail 99-108, comprising 19-21\% of body length; tail tip obtuse (Fig.6D). Posterior end of female 340 (340) wide, rounded in lateral view but squared off in dorsoventral view, provided with 2 large lateral papilla-like caudal projections 27 high (Fig. 6E-G). 

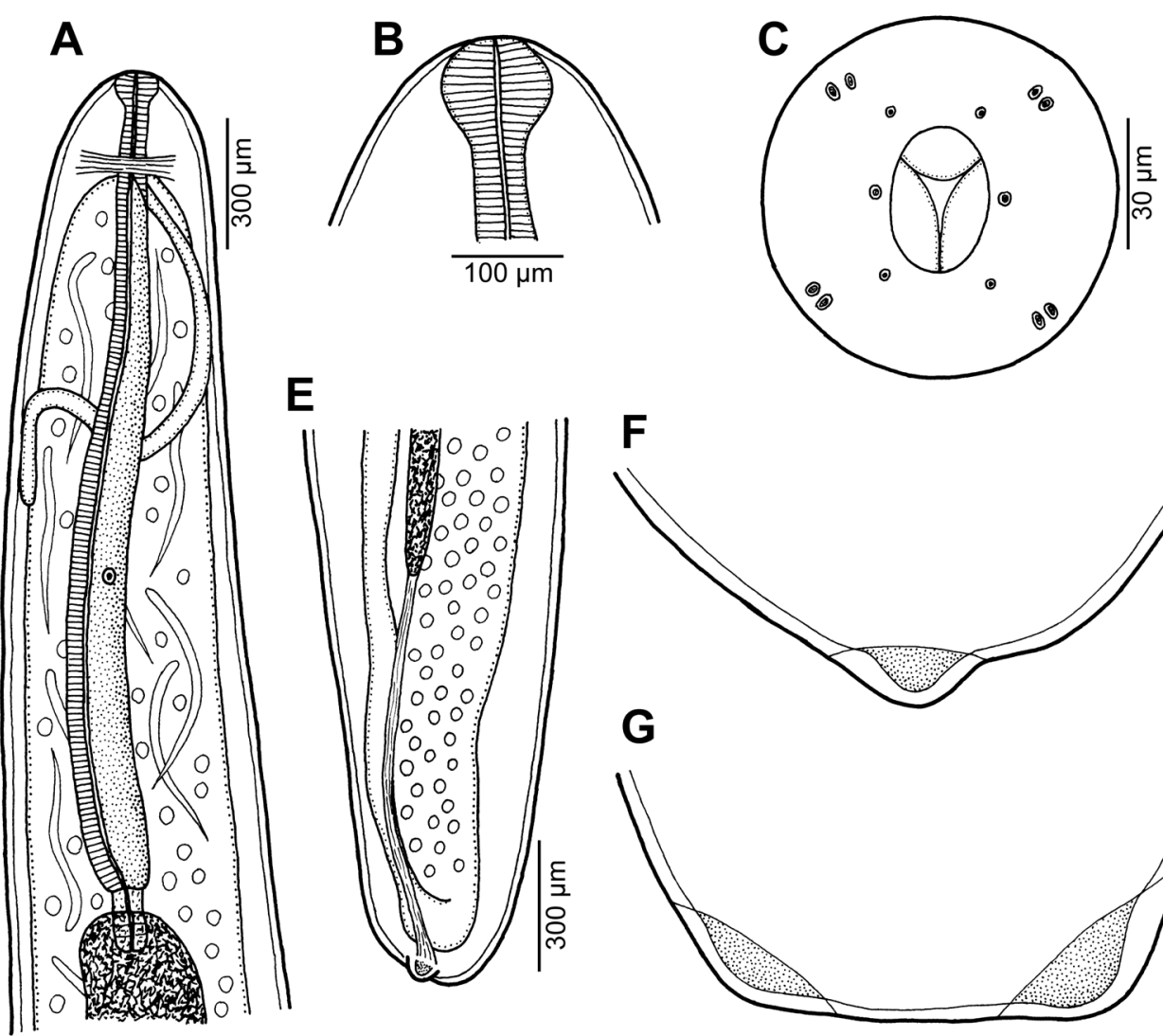

E
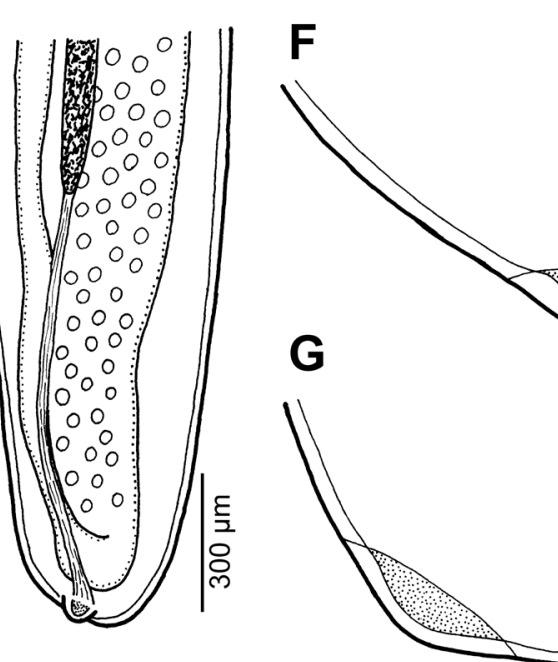

Fig. 6. Philometra papillicaudata sp. n. from the tissues of Lutjanus sebae (Cuvier), gravid female. A - anterior end of body, lateral view; B, C - cephalic end, lateral and apical views, respectively; D - larva from uterus, lateral view; $\mathbf{E}$ - posterior end of body, lateral view; F, G - caudal end, lateral and dorsoventral views, respectively.

\section{Male. Not known.}

Type host: Emperor red snapper, Lutjanus sebae (Cuvier) (Perciformes: Lutjanidae).

Site of infection: Tissue behind gills.

Type locality: Gulf of Carpentaria, off northern Australia (collected 6 August 2015).

Prevalence and intensity: 1.7\% (2 fish infected/120 fish examined); 1 and 4 nematodes.

Deposition of type specimens: SAM Cat. No. AHC 48209 (holotype); IPCAS Cat. No. N-1150 (paratype).

Etymology: The scientific name of this species papillicaudata is a Latin adjective derived from the nouns papilla (= papilla, tubercle) and cauda (= tail), relating to the presence of two large papilla-like projections on the female caudal end.

Remarks. In addition to morphological features, individual species of Philometra are characterised by their location in the host, particularly that of gravid females (Moravec 2004, Moravec and de Buron 2013). Moravec and Bakenhaster (2010) reported that only 13 of the very many nominal species of Philometra have their gravid females parasitic in the host's subcutaneous tissues, fins or the tissues of the buccal cavity, gill cover and gill arches of marine and brackish-water fishes. However, two additional species, P. macrochiri Moravec et Diggles, 2014 and $P$. gracilis Moravec et Barton, 2016, from the fins of Polydactylus macrochir (Günther) (Polynaemidae) and from the tissues behind the gills of Lutjanus johnii (Bloch), respectively, both off northern Australia, have been described since (Moravec and Diggles 2014b, Moravec and Barton 2016). With the exception of P. diplectri Moravec et Bakenhaster, 2010, all these species were described solely from females and their conspecific males remain unknown to date.

Only two of the above-mentioned tissue-dwelling species of Philometra have been described from fishes of the family Lutjanidae: P. brevispicula Moravec et Bakenhaster, 2010 from the mouth tissues of Lutjanus griseus in Florida Bay, USA (Moravec and Bakenhaster 2010) and P. gracilis (see above). Of these, P. brevispicula differs from the new species mainly in that its oesophageal gland extends far anterior to the nerve ring, where it forms a marked extension ( $v s$ the gland extends anteriorly only to the level of the nerve ring). In addition, its gravid females are distinctly shorter (28-44 mm vs $70 \mathrm{~mm}$ long), with very small caudal projections.

The oesophageal gland of $P$. gracilis extends anteriorly only to the level of the nerve ring as in the new species, but its gravid females are distinctly shorter (28-42 $\mathrm{mm}$ vs $70 \mathrm{~mm}$ long), with a somewhat shorter oesophagus representing 4-6\% (vs 3\%) of the entire body length, caudal projections are larger and more prominent (projections $41-68 \mu \mathrm{m} v s 27 \mu \mathrm{m}$ high) and the tail tip of larvae is sharply pointed ( $v s$ markedly obtuse). We consider these differences to be sufficient to establish a new species, $P$. papillicaudata sp. n., for the present nematodes from L. sebae. 

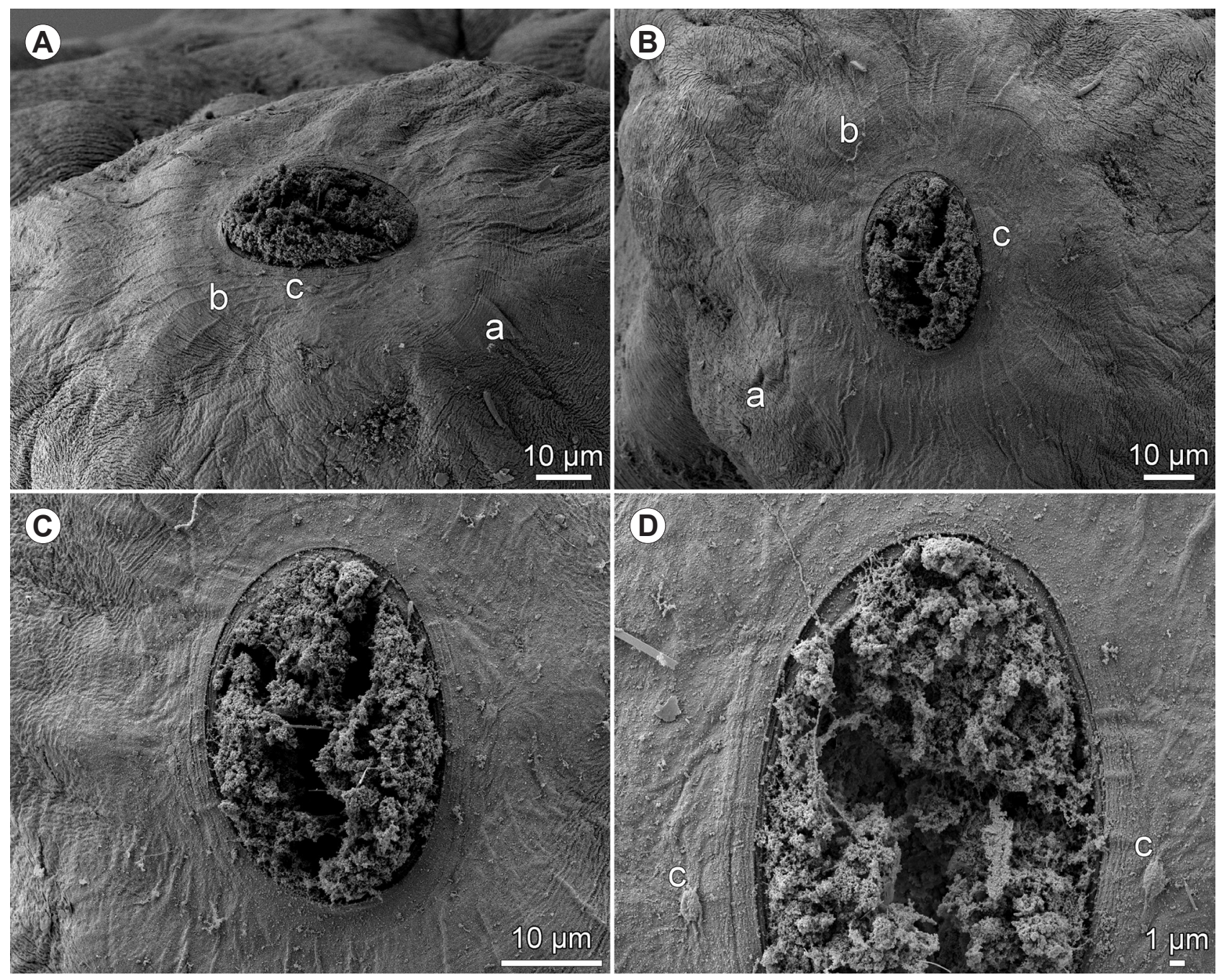

Fig. 7. Philometra papillicaudata sp. n. from the tissues of Lutjanus sebae (Cuvier), scanning electron micrographs of gravid female. A, B - cephalic end, sublateral and apical views, respectively; C - region of oral aperture, apical view; D - same, enlarged (note rim of oral aperture without denticles). Abbreviations: a - submedian pair of cephalic papillae of external circle; $\mathrm{b}$ - submedian cephalic papilla of internal circle; $\mathrm{c}$ - lateral cephalic papilla of internal circle.

It can be expected that more interspecific morphological features will be available when the males of $P$. gracilis and $P$. papillicaudata are discovered and described.

\section{Philometra sp.}

Figs. 8, 9

Description of subgravid female (1 ovigerous specimen). Body of fixed specimen brown, with distinct darkbrown intestine visible through cuticle, ends rounded. Posterior part of body somewhat narrower than anterior part; maximum width in region just posterior to oesophagus. Cuticle smooth. Body length $35 \mathrm{~mm}$, maximum width 653; maximum width/body length ratio $1: 54$. Width of cephalic end 177. Cephalic papillae small, indistinct when viewed laterally (Fig. 8A). Oral aperture almost circular, surrounded by small cephalic papillae arranged in 2 circles; inner circle consisting of 4 submedian and 2 lateral single papillae, outer circle formed by 4 submedian pairs of papillae; each pair of outer submedian papillae consisting of 1 circular and 1 elongate papilla; lateral amphids slightly outlined (Figs. 8B, 9A,B). Mouth with 3 rounded oesophageal lobes corresponding to 3 oesophageal sectors, each of them bear- ing small terminal sclerotised plate. Length of oesophagus including distinct anterior bulbous inflation 911 long, 2.6\% of body length; maximum width of posterior part of oesophagus including gland 82; anterior oesophagus inflation 109 long, 122 wide. Oesophageal gland well developed, opening into oesophagus just posterior to nerve ring, with large cell nucleus in middle. Nerve ring and oesophageal nucleus 231 and 612, respectively, from anterior extremity. Ventriculus small, 14 long, 82 wide. Posterior end of intestine attached by ligament to body wall near caudal end (Fig. 8C); length of ligament 952. Vulva and anus absent. Ovaries reflexed near body extremities. Uterus occupies most space of body, filled with eggs 15-20 in diameter (Fig. 8A,C). Posterior end rounded, 272 wide, with 2 very small lateral papilla-like caudal projections (Fig. 8C).

Host: Goldbanded jobfish, Pristipomoides multidens (Day) (Perciformes: Lutjanidae).

Site of infection: Ovary.

L o c a lit y: Joseph Bonaparte Gulf, off northern Australia (collected 3 August 2015). 

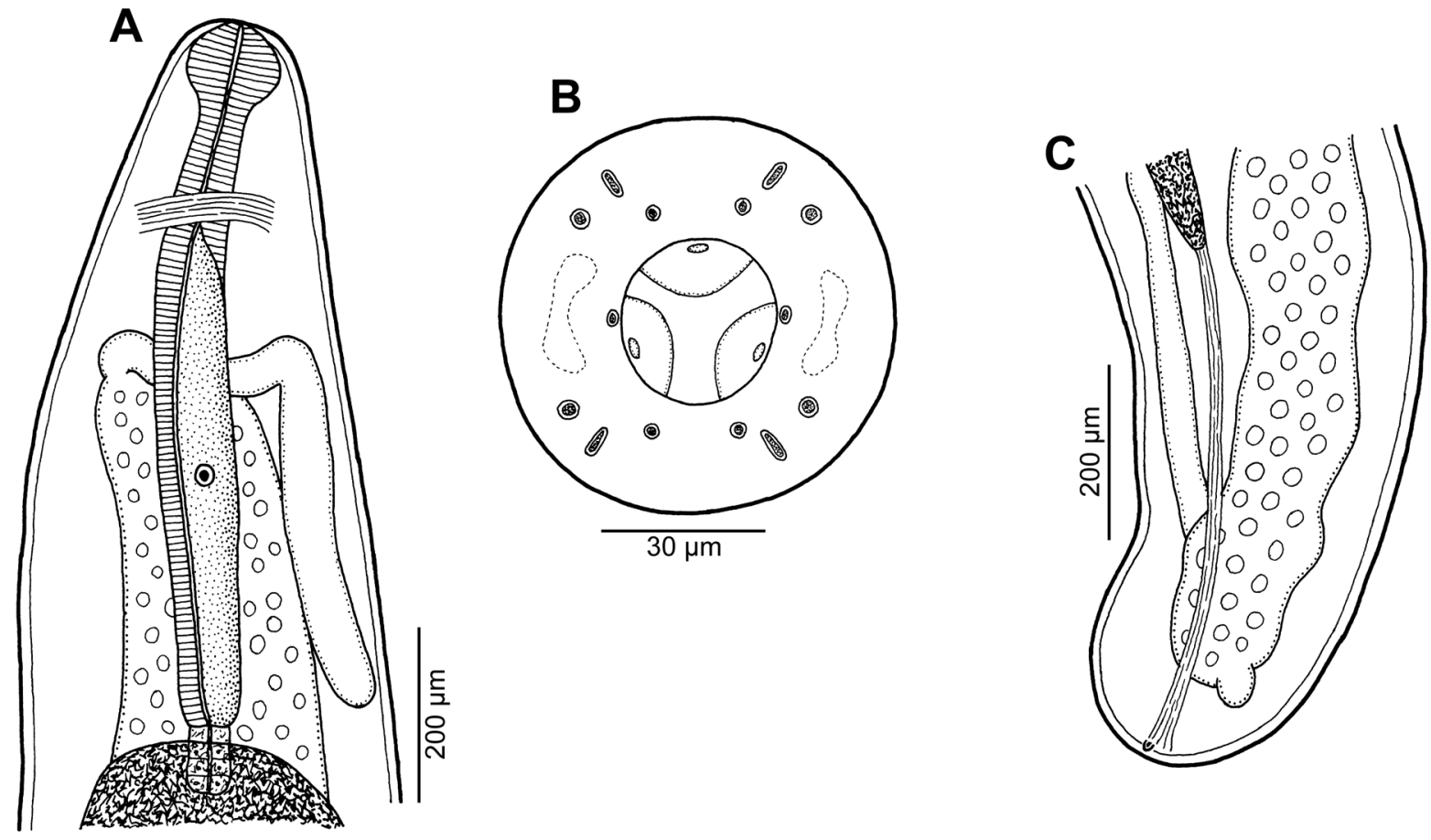

Fig. 8. Philometra sp. from the ovary of Pristipomoides multidens (Day), subgravid female. A - anterior end of body, lateral view; $\mathbf{B}$ - cephalic end, apical view; $\mathbf{C}$ - caudal end, lateral view.

Prevalence and intensity: $3 \%$ (1 fish infected/ 31 fish examined), $5 \%$ (1/20) in female fish only; 1 nematode.

Deposition of voucher specimen: SAM Cat. No. AHC 48212.

Remarks. Since only a single subgravid female specimen was found from the ovary of Pristipomoides multidens, its identification to species is impossible. No species of Philometra has so far been reported from Pristipomoides spp. Therefore, considering a high degree of host specificity of gonad-infecting species of Philometra (see above), it is highly probable that this specimen represents a hitherto undescribed species.

In addition to three nominal gonad-infecting species of Philometra (P. arafurensis sp. n., P. carponotati and $P$. mawsonae sp. n.) parasitising fishes of the Lutjanidae (all in Lutjanus spp.) in Australian waters, females of another species, reported as Philometra sp., were recorded in the ovary of Lutjanus johnii from off northern Australia (Moravec and Barton 2015). Kardousha (1999) reported philometrid females identified as $P$. lateolabracis (Yamaguti, 1935) from the ovary of the same host species (L. johnii) in the Persian Gulf, but in view of the revisionary paper of Quiazon et al. (2008) on P. lateolabracis, this was an apparent misidentification (Moravec and Barton 2015). It is highly probable that the nematodes reported by Kardousha (1999) and Moravec and Barton (2015) from L. johnii were conspecific, belonging to an undescribed species. However, this can be established only when conspecific males are available, because interspecific features of gonad-infecting philometrids depend mainly on male morphology.
Dentiphilometra malabarici sp. $\mathrm{n}$.

Figs. 10, 11

ZooBank number for species:

urn:lsid:zoobank.org:act:3A7B25B7-B4B7-4ED3-9044-87525BEFBBE6

Description of gravid female (6 complete and 2 incomplete larvigerous specimens; measurements of holotype in parentheses): Body of fixed specimens yellowish, ends rounded. Posterior part of body conspicuously narrower than anterior part; maximum width in region just posterior to oesophagus. Cuticle smooth. Body length 34 $72 \mathrm{~mm}$ (72 mm), maximum width 381-598 (558); maximum width/body length ratio $1: 85-129$ (1 : 129). Width of cephalic end 177-231 (218). Cephalic papillae small, indistinct when viewed laterally (Fig. 10B,E). Oral aperture oval, surrounded by distinct narrow sclerotised ring armed with numerous minute teeth on its surface; teeth approximately 0.5 high, arranged regularly in single row (Figs. 10A,F, 11A-D). Three lobular sectors of oesophagus projecting into mouth opening; these lack sclerotised tips. Oral aperture surrounded by 14 minute cephalic papillae arranged in 2 circles; inner circle consisting of 4 submedian and 2 lateral single papillae, outer circle formed by 4 submedian pairs of papillae; amphids not observed (Figs. 10A, 11A,B). Length of oesophagus including distinct anterior bulbous inflation $1.85-2.05 \mathrm{~mm}(1.90 \mathrm{~mm})$ long, 2.6-6.0\% (2.6\%) of body length; maximum width of posterior part of oesophagus including gland 122-163 (163); anterior oesophageal inflation 82-122 (122) long, 109-150 (150) wide. Oesophageal gland well developed, opening into oesophagus just posterior to nerve ring, with large cell nucleus in middle. Nerve ring and oesophageal nucleus 286-326 (326) and 1.12-1.36 mm (1.12 mm), 


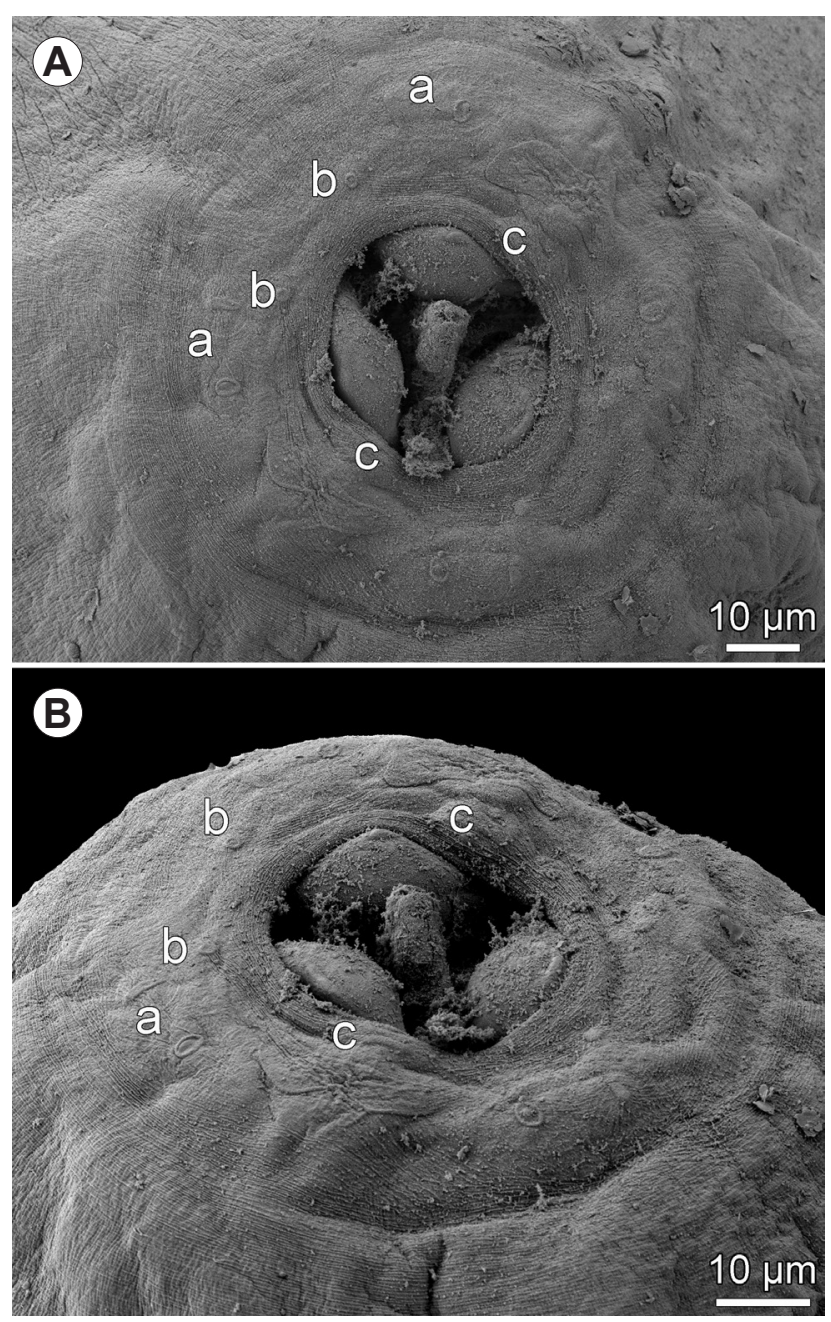

Fig. 9. Philometra sp. from Pristipomoides multidens (Day), scanning electron micrographs of cephalic end of subgravid female. A - apical view; B - sublateral view. Abbreviations: a submedian pair of cephalic papillae of external circle; $b$ - submedian cephalic papilla of internal circle; $\mathrm{c}$ - lateral cephalic papilla of internal circle.

respectively, from anterior extremity. Ventriculus small, 27-54 (54) long, 54-82 (82) wide. Intestine light-brown, narrow, its posterior end attached by ligament to body wall near caudal end (Fig. 10C,J); length of ligament 1.03-1.78 $\mathrm{mm}(1.78 \mathrm{~mm})$. Vulva and anus absent. Ovaries reflexed near body extremities. Uterus occupies most space of body, filled with numerous eggs and larvae (Fig. 10C,E,G,J). Larvae $(\mathrm{n}=5)$ 513-561 long and 21-24 wide; oesophagus $135-156$ long, comprising $24-29 \%$ of body length; length of sharply pointed tail $87-96$, comprising $16-18 \%$ of body length (Fig. 10G). Posterior end of female 109-190 (150) wide, with 2 large lateral papilla-like caudal projections 18-39 (33) high (Figs. 10G-J, 11E,F).

Subgravid female (3 ovigerous specimens). Body length 24-42 mm, maximum width 313-408; maximum body width/length ratio $1: 98-103$. Width of cephalic end 150-190. Number and arrangement of cephalic papillae as in gravid specimens. Oesophagus including anterior inflation $1.32-1.43 \mathrm{~mm}$ long, $4.2-5.5 \%$ of body length; maximum width of posterior part of oesophagus including gland
82-95; anterior oesophageal inflation 82-109 long and 95122 wide. Nerve ring and oesophageal nucleus 245-272 and $966-1,224$, respectively, from anterior extremity. Ventriculus 27-54 long, 54-68 wide. Length of intestinal ligament $1.12-1.40 \mathrm{~mm}$. Vulva and anus absent. Uterus filled with numerous eggs. Posterior end $95-150$ wide, with 2 large lateral papilla-like caudal projections 18-27 high.

Nongravid female (4 mature specimens with empty uterus). Body length $4.28-9.93 \mathrm{~mm}$, maximum width 82-136; maximum width/body length ratio $1: 51-81$. Width of cephalic end 68-109. Cephalic structures as in gravid specimens. Oesophagus, with inflation at anterior end, $0.90-1.29$ long, $13.0-23 \%$ of body length (Fig. 10D); maximum width of posterior part of oesophagus including gland 27-68. Nerve ring and oesophageal nucleus 177-204 and 503-830, respectively, from anterior extremity. Length of intestinal ligament 503-993. Uterus empty. Caudal end rounded, 41-82 wide, with large lateral papilla-like caudal projections 12-18 high (Fig. 10K).

Male. Not known.

Type host: Malabar blood snapper, Lutjanus malabaricus (Bloch et Schneider) (Perciformes: Lutjanidae).

Site of infection: Tissues behind gills.

Type locality: Gulf of Carpentaria, northern Australia (collected 21 August 2015).

Other localities: Joseph Bonaparte Gulf (collected 3 August 2015), Arafura Sea East (collected 14 August 2015), Arafura Sea West (collected 22 April 2016) and Timor Reef Fishery (collected 16 September 2015 and 28 October 2016), all off northern Australia.

Total prevalence and intensity: 34\% (52 fish infected/151 fish examined); 1-8 (mean 2) nematodes per fish.

Deposition of type specimens: SAM Cat. No. AHC 48210 (holotype) and AHC 48211 (paratypes); IPCAS Cat. No. N-1151 (paratypes).

Etymology: The scientific name malabarici is the genitive form of the Latin adjective malabaricus and relates to the host species of this nematode, i.e. Lutjanus malabaricus.

Remarks. The general structure of these nematodes, especially the presence of circumoral teeth, shows that they belong to Dentiphilometra. At present this genus contains only two species, D. monopteri Moravec et Wang, 2002 (type species), a parasite of the body cavity of the freshwater swamp eel Monopterus albus (Zuiew) (Synbranchidae) in China (Moravec and Wang 2002), and D. lutjani González-Solís, Moravec et Tuz Paredes, 2007 parasitic in the musculature of the marine fish Lutjanus griseus off the Caribbean coast of Mexico (González-Solís et al. 2007). Whereas the former species was established based on both males and gravid females, the latter one was described solely from available gravid and subgravid females.

Dentiphilometra monopteri distinctly differs from $D$. lutjani and the new species in the extent of its dorsal oesophageal gland in gravid females, which extends far anterior to the level of the nerve ring ( $v s$ the gland extends only just posterior to the level of the nerve ring), each of three oesophageal lobes in the mouth is provided with a terminal sclerotised tooth ( $v s$ sclerotised teeth are absent on 

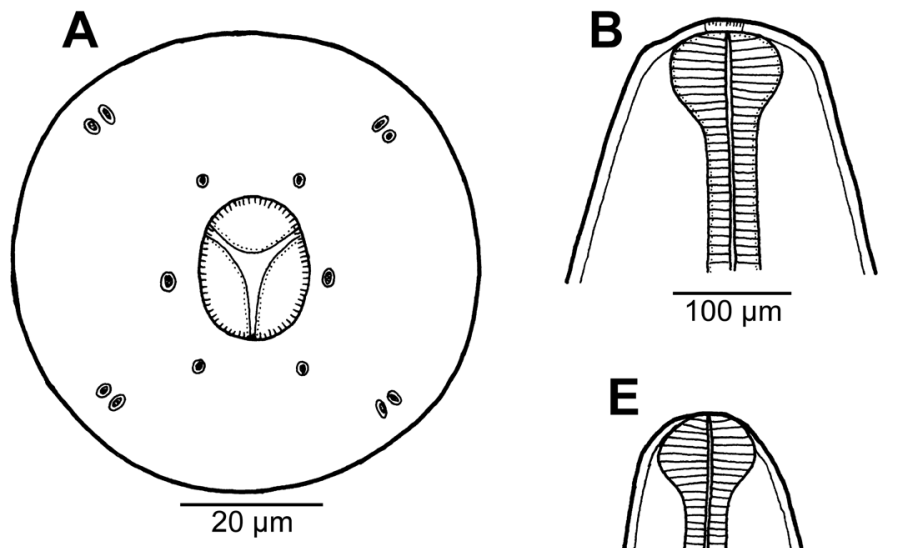

C
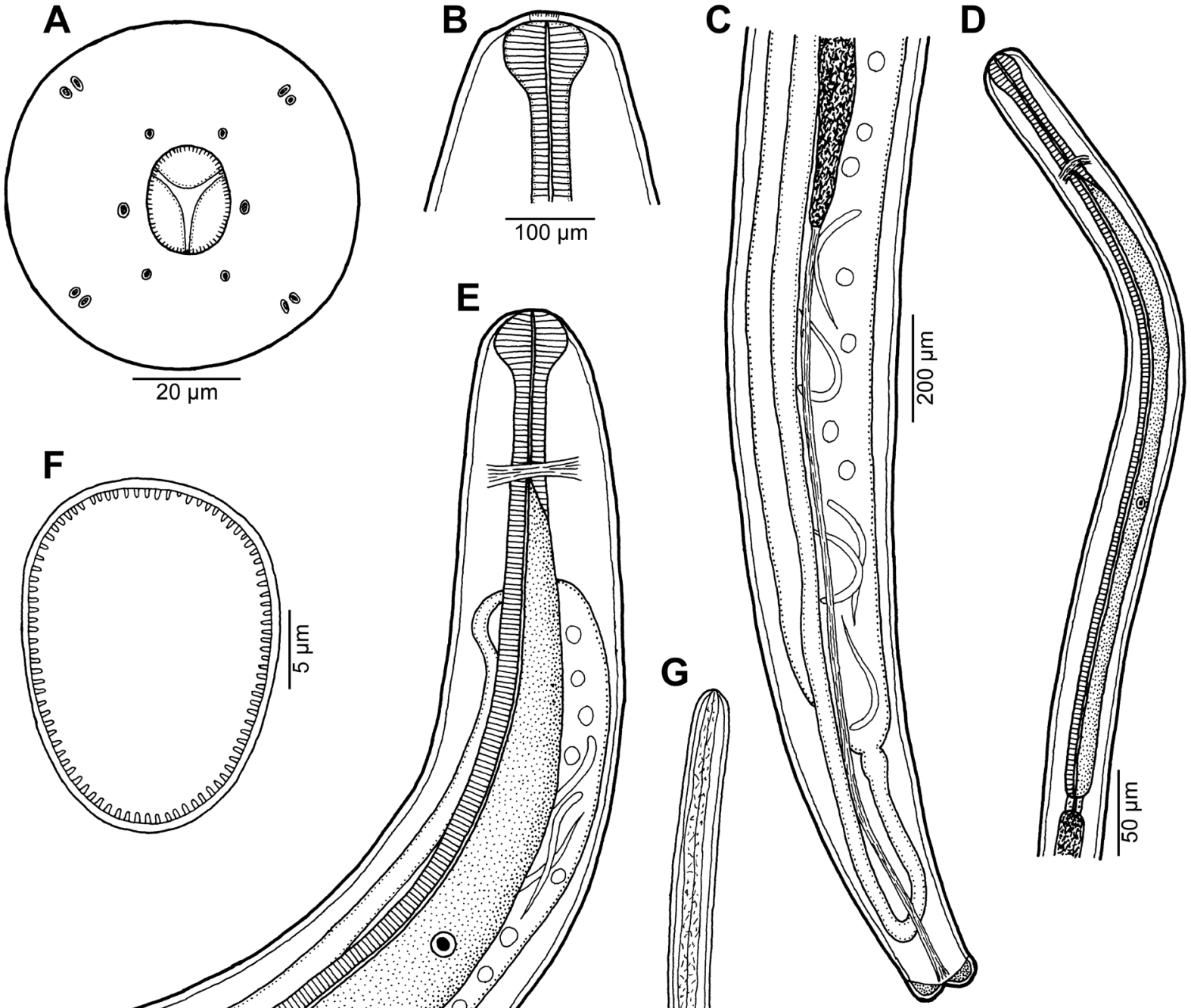

E
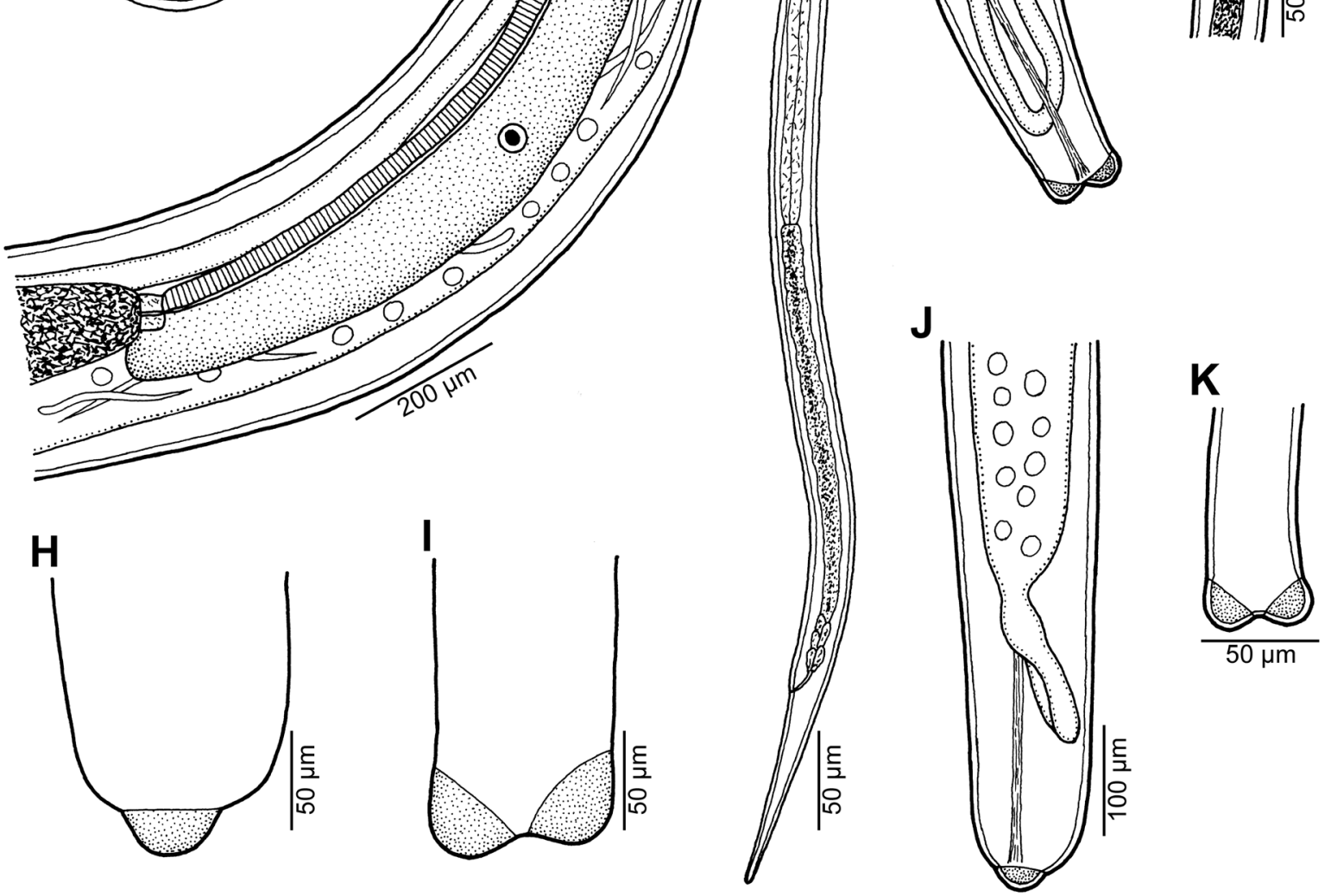

Fig. 10. Dentiphilometra malabarici sp. n. from the tissue of Lutjanus malabaricus (Bloch et Schneider), female. A, B - cephalic end of gravid specimen, apical and lateral views, respectively; $\mathbf{C}$ - posterior end of gravid specimen, dorsoventral view; $\mathbf{D}$ - anterior end of nongravid specimen (body length $40 \mathrm{~mm}$ ), lateral view; $\mathbf{E}$ - anterior end of gravid specimen, lateral view; $\mathbf{F}$ - oral aperture of gravid specimen, apical view; G - larva from uterus, lateral view; H, I - caudal papillae of gravid female, lateral and dorsoventral views, respectively; $\mathbf{J}$ - posterior end of gravid specimen, lateral view; $\mathbf{K}$ - caudal end of nongravid female, dorsoventral view. 

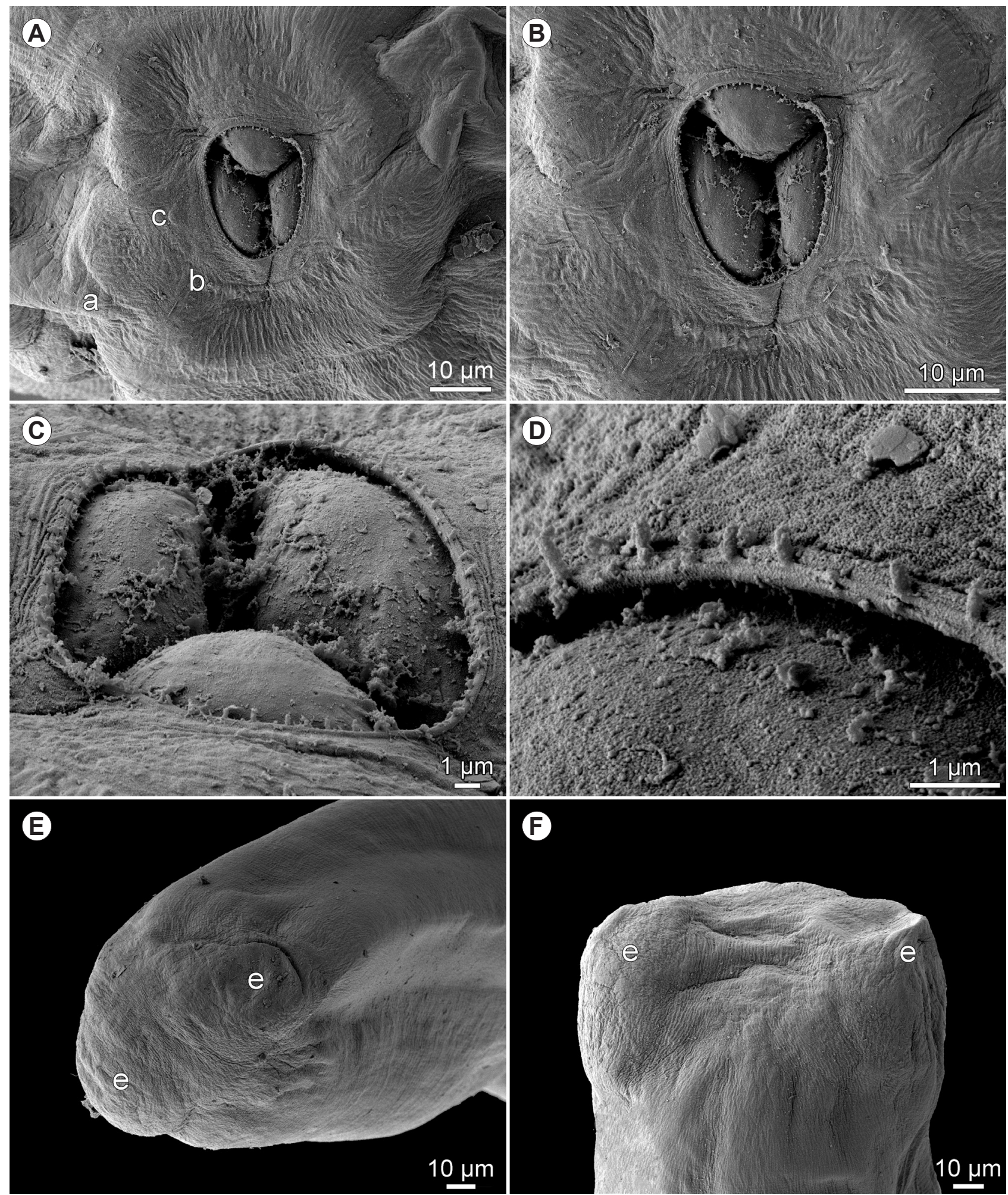

\section{$\boldsymbol{P}$}

Fig. 11. Dentiphilometra malabarici sp. n. from the tissue of Lutjanus malabaricus (Bloch et Schneider), scanning electron micrographs of gravid female. A - cephalic end, apical view; B - same, larger magnification; $\mathbf{C}$ - oral aperture, subapical view; $\mathbf{D}$ - detail of rim of oral aperture with denticles; $\mathbf{E}, \mathbf{F}$ - caudal end, subapical and dorsoventral views, respectively. Abbreviations: a - submedian pair of cephalic papillae of external circle; $b$ - submedian cephalic papilla of internal circle; $c$ - lateral cephalic papilla of internal circle; e - caudal projection.

oesophageal lobes), the site of infection in the host is different (abdominal cavity vs musculature or tissues behind gills), as well as the environment (freshwater vs marine) and their hosts also belong to different fish orders (Synbranchiformes vs Perciformes).

The new species is morphologically more similar to D. lutjani and also their hosts belong to the same fish 
genus. However, it differs from the latter species in that there is no protuberance at the top of each of the three oesophageal lobes in the mouth (vs such protuberances are present), circumoral teeth are arranged in one row ( $v s$ in two to three rows), caudal projections are mostly larger, 18-39 $\mu \mathrm{m}$ (vs 12-18 $\mu \mathrm{m})$ high, larvae from the uterus are longer (513-561 $\mu \mathrm{m}$ vs 344-483 $\mu \mathrm{m}$ long) and both species occur in distant geographical regions (off northern coast of Australia vs Caribbean Sea, Mexico).

\section{Digitiphilometroides gen. n.}

ZooBank number for genus:

urn:1sid:zoobank.org:act:AE47CD15-58C8-4639-9EDF-FA7709548E5A

Diagnosis. Philometridae. Body of females elongated, cylindrical, with bluntly rounded ends. Anterior part of body with numerous, irregularly distributed small cuticular bosses; posterior part of body with numerous, rather long longitudinal rows of cuticular ornamentations formed by mostly circular groups of numerous minute digitiform projections. Cephalic end with four large dome-shaped submedian projections. Cephalic papillae small, arranged in two circles. Oesophagus cylindrical, expanded at anterior end; dorsal oesophageal gland large, mononucleate; small ventriculus present. Vulva and anus in gravid females atrophied. Ovaries in both body ends. Males not known. Parasites of body cavity of marine fishes.

Type and the only species: Digitiphilometroides marinus (Moravec et de Buron, 2009) comb. $n$.

Etymology: This generic name is composed of two parts, Digiti (= digits, fingers) and Philometroides (= one of the related philometrid genera), and relates to the unique feature of this genus, i.e. the presence of digital cuticular ornamentations.

Digitiphilometroides marinus (Moravec et de Buron, 2009) comb. n.

Figs. 12-14

Syn. Philometroides marinus (Moravec et de Buron, 2009)

Description of subgravid female (1 ovigerous specimen). Body of fixed specimen brownish, filiform, $32.3 \mathrm{~cm}$ long, maximum width $1.21 \mathrm{~mm}$; width of cephalic end 286 , width of caudal end 313; posterior part of body narrower than anterior part. Maximum width/body length ratio 1 : 267. Anterior part of body covered with small, irregularly scattered circular to somewhat transversely elongate cuticular bosses up to 9 high (Figs. 12A,C-E, 13E, 14A); embossment starts immediately posterior to cephalic projections and finishes at distance equal to approximately 3 lengths of oesophagus; posterior part of body with numerous, rather long longitudinal rows of cuticular ornamentations formed by mostly circular groups of numerous minute digital formations (Figs. 12F,G, 13F,G, 14B-D); this ornamentation finishes at short distance from posterior extremity, but its beginning not determined. Cephalic end blunt, provided with 4 large, forwardly protruding submedian dome-shaped projections, each of them sepa- rated into 2 parts by slightly depressed submedian groove (Figs. 12A,B,D, 13A,B,D,E). Oral aperture small, circular, surrounded by 14 small cephalic papillae arranged in 2 circles; external circle formed by 4 submedian pairs of papillae, each pair being located on large cephalic projection; internal circle consists of 4 submedian and 2 lateral single papillae (Figs. 12B, 13A,B,D); amphids indistinct. Three lobular sectors of oesophagus projecting into mouth opening. Oesophagus muscular, forming distinct bulb at anterior end, with conspicuously large oesophageal gland extending from level of nerve ring to end of oesophagus, possessing large cell nucleus at its middle; oesophagus including bulb $1.99 \mathrm{~mm}$ long, representing $0.6 \%$ of body length, maximum width (including oesophageal gland) 408; anterior bulbous inflation 177 long and 190 wide; cell nucleus of dorsal oesophageal gland $1.59 \mathrm{~mm}$ from anterior extremity (Fig. 12A). Nerve ring 340 from anterior end of body. Ventriculus small, 54 long and 122 wide, opening into intestine through valve. Intestine brown, straight; anterior end of intestine narrow, posterior end atrophied; its posterior end attached by ligament to body wall near caudal end (Fig. 12H,I). Vulva and anus absent. Ovaries narrow, long, reflexed near body extremities (Fig. 12A,H,I). Uterus occupies most space of body, filled with numerous eggs. Caudal end of body obtuse, with 2 large lateral papilla-like projections 54 long (Figs. 12H,I, 13C,G).

Host: Cobia, Rachycentron canadum (Linnaeus) (Perciformes: Rachycentridae).

Site of infection: Body cavity (mesentery near rectum).

Locality: Timor Reef Fishery (10²4'00"S; 13049'12"E) (collected 14 September 2016).

Prevalence and intensity: 10\% (1 fish infected/10 fish examined); 1 nematode.

Deposition of voucher specimen: IPCAS Cat. No. N-903.

Remarks. The present Australian nematode seemed to be morphologically very similar to Philometroides marinus Moravec et de Buron, 2009, a species described from female specimens collected in the body cavity of the same fish host (Rachycentron canadum) off the Atlantic coast of South Carolina, USA (Moravec and de Buron 2009). The only exception was the presence of cuticular ornamentations on the posterior part of the body, formed by groups of numerous minute digital formations, which were not mentioned in the original description of $P$. marinus. However, a re-examination of the holotype of $P$. marinus (IPCAS Cat. No. N-903 ) showed the presence of the same cuticular structures on it. While describing $P$. marinus, these unusual structures on the nematode posterior end were probably considered to be artefacts. Therefore, the Australian specimen and those reported as $P$. marinus from off the USA belong to the same species.

The cuticular ornamentation on the posterior part of the body of $P$. marinus, i.e. the presence of groups of digital formations, is unique within all species of the Philometridae. Among the Dracunculoidea, somewhat similar cuticular formations occur only in species of Micropleura of Linstow, 1906 (Micropleuridae), parasites of the body cavity of crocodilians (Moravec 2001, Moravec and Prouza 


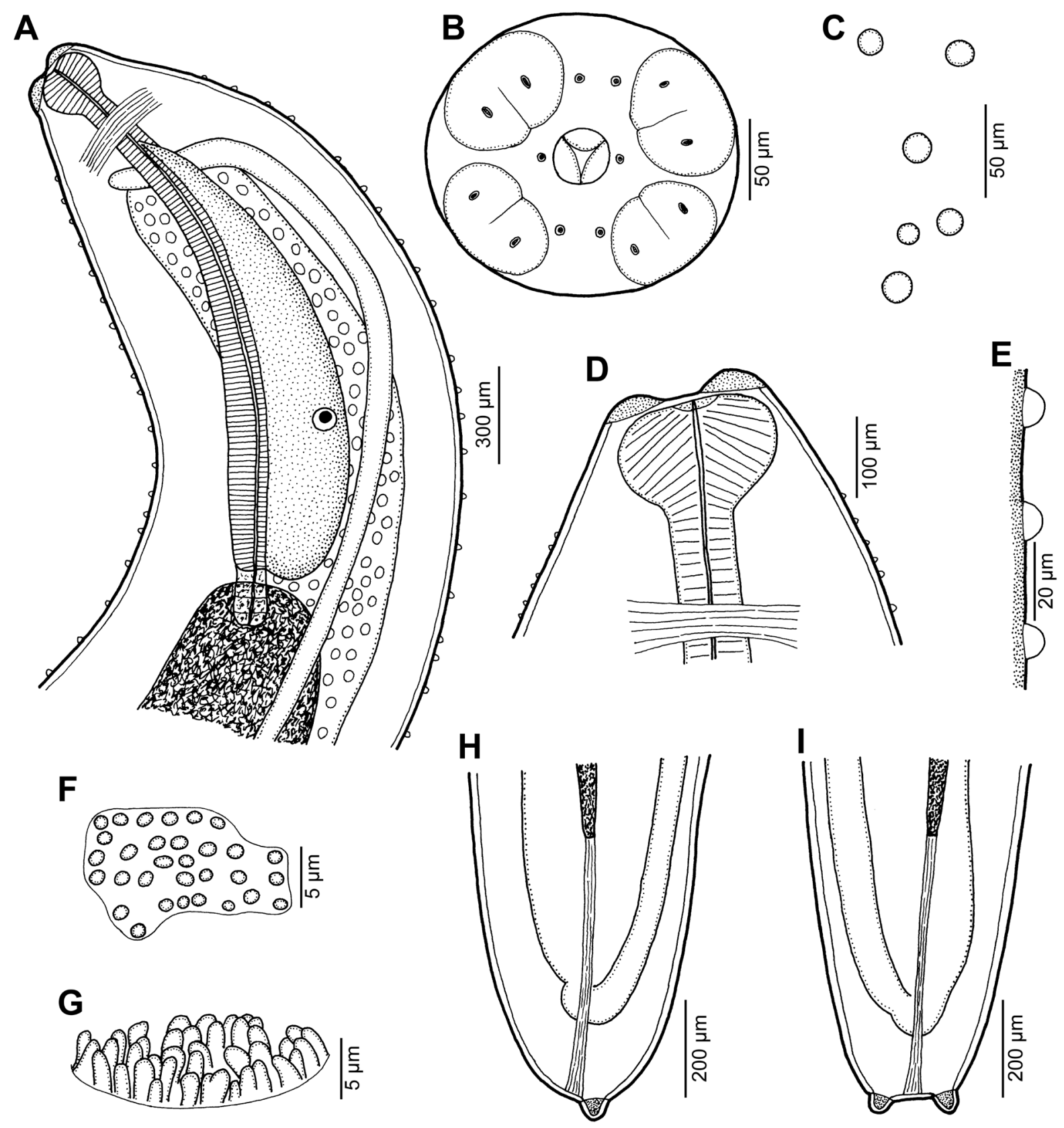

Fig. 12. Digitiphilometroides marinus (Moravec et de Buron, 2009) comb. n., subgravid female from body cavity of Rachycentron canadum (Linnaeus). A - anterior end of body, lateral view; B - cephalic end, apical view; C - cuticular bosses on anterior part of body, apical view; D - cephalic end, lateral view; $\mathbf{E}$ - cuticular bosses on anterior part of body, lateral view; $\mathbf{F}, \mathbf{G}$ - cuticular formation on posterior part of body, apical and sublateral views, respectively; H, I - caudal end, lateral and dorsoventral views, respectively

2003, Moravec et al. 2004, Junker and Mutafchiev 2017), which indicates affinities of the Philometridae with the Micropleuridae. Since the presence/absence and character of the female cuticular ornamentation are used as an important intergeneric criterion in the taxonomy of philometrids (Rasheed 1963, Ivashkin et al. 1971, Chabaud 1975, Moravec 2006, Gibbons 2010, Moravec and de Buron 2013), we propose a new genus, Digitiphilometroides, to accommodate this species.

As Philometroides marinus mentioned above, Digitiphilometroides marinus comb. $\mathrm{n}$. was originally described from R. canadum off the Atlantic coast of South Carolina, USA and only recently it has been reported from the same host species off Bali (Indian Ocean), Indonesia (Dewi and Palm 2017). Consequently, the present finding represents the third record of this nematode species and the first one in Australian waters. Records of this parasite in the western Atlantic, Australia and Indonesia suggest that the distribution area of $D$. marinus coincides with that of its definitive host. The same pattern has recently been recorded by Barton et al. (2018) for another parasite, the acanthocephalan Serrasentis sagittifer (Linton, 1889). This species was originally described from $R$. canadum in North Carolina, USA, and it has been redescribed from specimens collected from the same fish host species in northern Australia (Barton et al. 2018). Rachycentron canadum has 


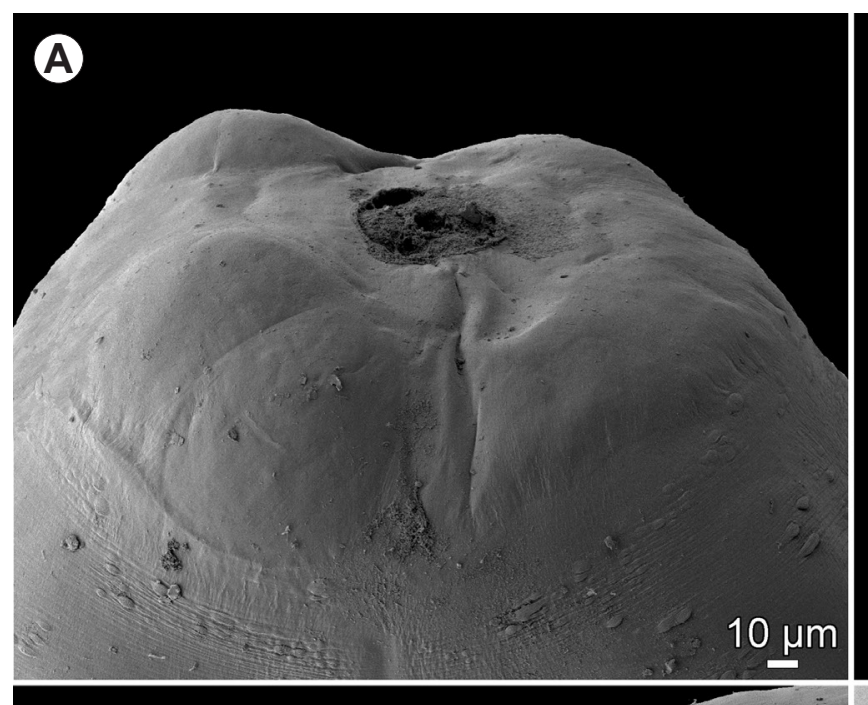

(B)
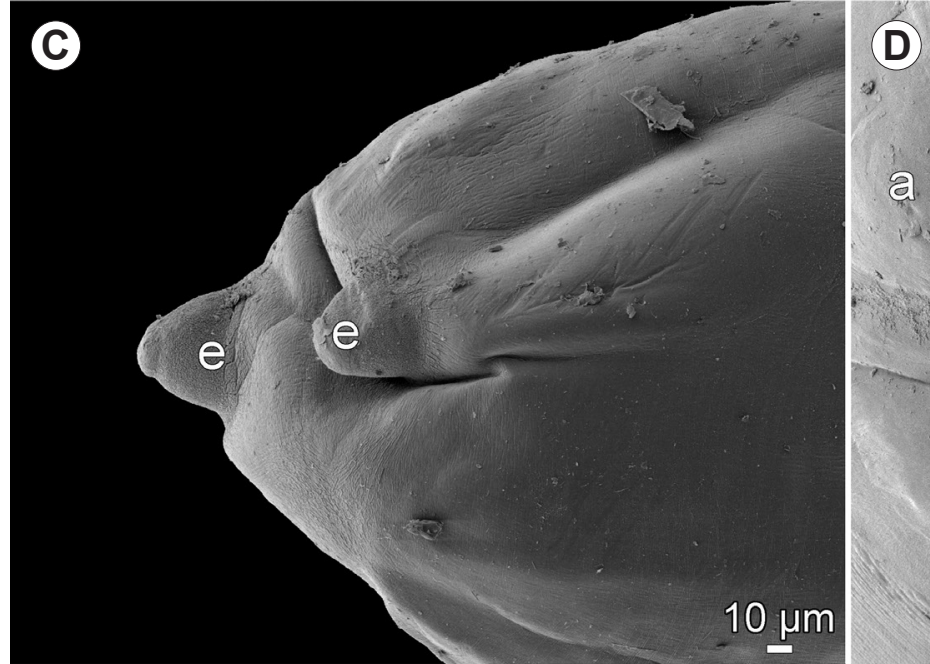

(D)

2

a

b

b

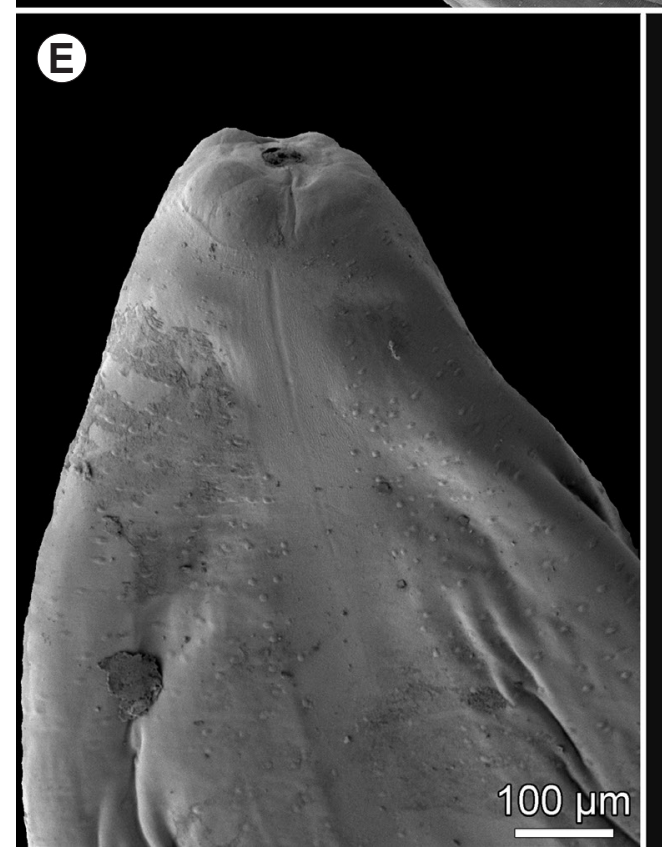

\section{(F)}

-

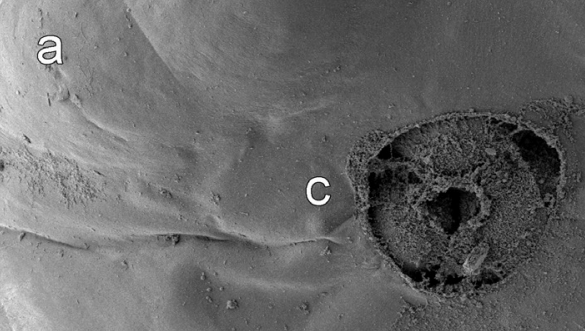

C

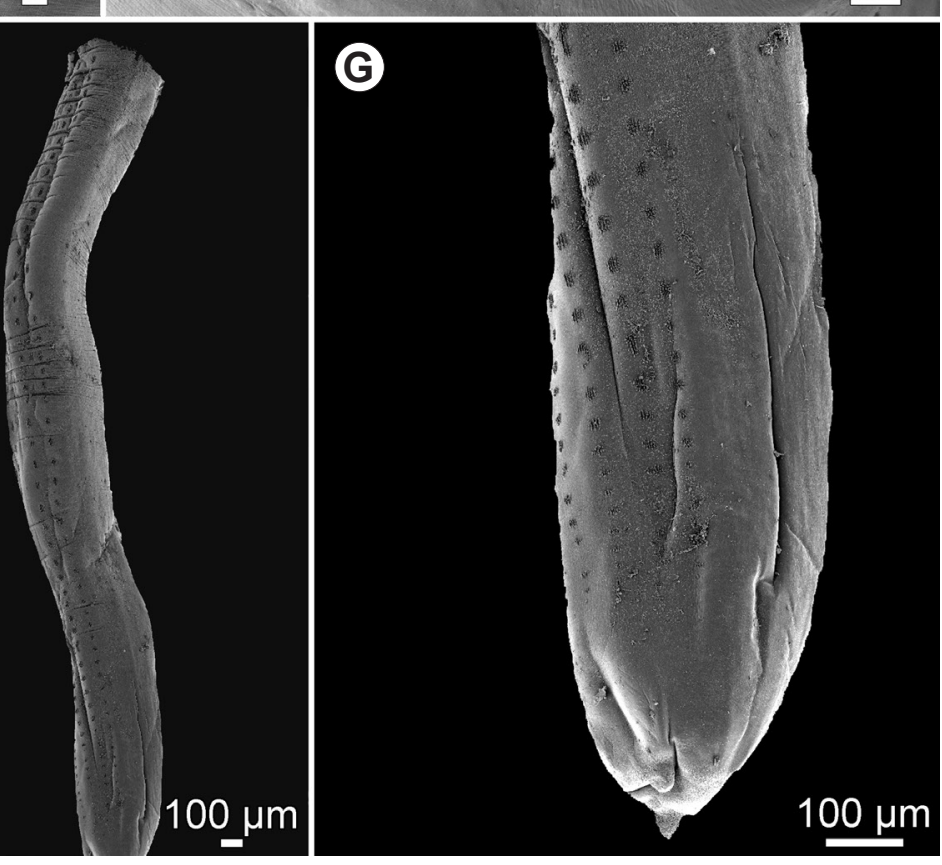

Fig. 13. Digitiphilometroides marinus (Moravec et de Buron, 2009) comb. n. from body cavity of Rachycentron canadum (Linnaeus), scanning electron micrographs of subgravid female. A, B - cephalic end, sublateral and apical views, respectively; C - caudal end, lateral view; D - cephalic end, apical view (larger magnification); $\mathbf{E}$ - anterior end of body, lateral view; $\mathbf{F}$ - cuticular ornamentations on posterior part of body, lateral view; $\mathbf{G}$ - posterior end of body, lateral view. Abbreviations: a - submedian cephalic papilla of external circle; $b$ - submedian cephalic papilla of internal circle; $\mathrm{c}$ - lateral cephalic papilla of internal circle; $\mathrm{e}$ - caudal projection. 


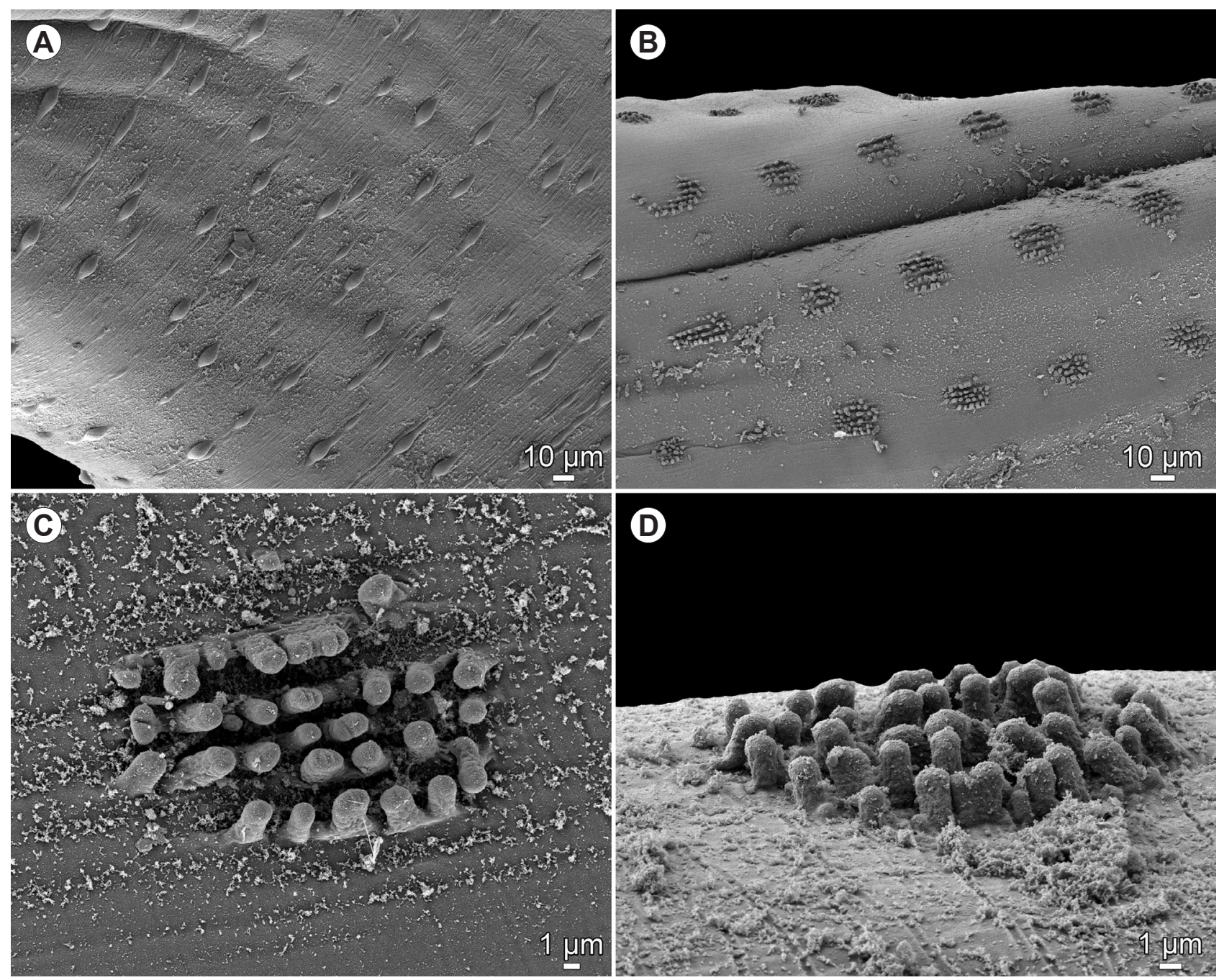

Fig. 14. Digitiphilometroides marinus (Moravec et de Buron, 2009) comb. n. from body cavity of Rachycentron canadum (Linnaeus), scanning electron micrographs of subgravid female. A - cuticular bosses on anterior part of body; $\mathbf{B}$ - cuticular ornamentations on posterior part of body; C, D - enlarged cuticular ornamentation on posterior part of body, apical and lateral views, respectively.

a worldwide distribution in tropical and subtropical waters, but is absent in the eastern Pacific and the Pacific Plate, except marginally (Froese and Pauly 2017).

\section{DISCUSSION}

To date, a total of 24 nominal species of philometrids (including those reported in this paper), belonging to six genera, has been recorded from marine and brackish-water fishes off Australia: Buckleyella Rasheed, 1963 (one species), Dentiphilometra (one species), Digitiphilometroides gen.n. (one species), Philometra (17 species), Philometroides Yamaguti, 1935 (three species) and Spirophilometra Parukhin, 1971 (one species). However, most of these species $(20$, i.e. $83 \%)$ were described within the last four years (since 2014). Considering the diversity and the high number of fish species occurring in Australian sea waters and the high degree of host specificity of philometrids, this indicates that the hitherto known species of these parasites represent only a very small part of the Australian fauna of these nematodes.
Unfortunately, a great majority of the species are known solely by females, whereas conspecific males were described only for six gonad-infecting species of Philometra. One species, Philometra percalates Johnston et Mawson, 1940, was inadequately described from a single available male and the site of infection in the host was not given (Johnston and Mawson 1940). Moravec and Diggles (2014b) reported Philometra johnii Moravec et Ali, 2013 from the ovary of the croaker Johnius sp. (Sciaenidae) in Australia, a species originally described from Johnius dussumieri (Cuvier) in the Persian Gulf, but because no males were available, this identification needs to be confirmed by subsequent studies.

The presence of three morphologically different gonad-infecting species of Philometra, P. arafurensis sp. n., $P$. carponotati and $P$. mawsonae sp. n., in different species of congeneric hosts (Lutjanus spp.) from Australian waters (Moravec and Diggles 2014a, present study) confirms the high degree of host specificity of these nematodes previously observed in Lutjanus spp. in the Gulf of Mexico (Moravec et al. 2014) and in the Bay of Bengal 
(Moravec and Manoharan 2014); the same phenomenon was observed in Epinephelus spp. (Serranidae) from different regions (see Moravec et al. 2016). Therefore, it is highly probable that the female philometrids from the ovary of Lutjanus johnii off Australia reported as Philometra sp. by Moravec and Barton (2015) as well as the female of Philometra sp. from Pristipomoides multidens reported in this paper will prove to represent additional new species.

Acknowledgements. We thank the vessels, captains and crew of the various boats within the Northern Territory Timor Reef and Demersal Fisheries for the collection of fish. Fish collection was conducted under Charles Darwin University Animal Ethics Approval A13014. The project was funded by the licence holders of the Northern Territory Timor Reef and Demersal Fisheries and the Northern Territory Department of Primary Industries and Resources Fisheries Division. Thanks are also due to the Laboratory of Electron Microscopy, Institute of Parasitology, Biology Centre CAS, institution supported by the MEYS CR (LM2015062 Czech-BioImaging) for their support with obtaining scientific data presented in this paper, and to Blanka Škoríková of the same Institute for help with the illustrations. This study was partly supported by the Czech Science Foundation (Grant. No. P505/12G112) and by institutional support (RVO: 60077344, Institute of Parasitology, BC CAS).

\section{REFERENCES}

Barton D.P., Smales L., Morgan J.A.T. 2018: A redescription of Serrasentis sagittifer (Rhadinorhynchidae: Serrasentinae) from Rachycentron canadum (Rachycentridae) with comments on its biology and its relationship to other species of Serransentis. J. Parasitol. 104: 117-132.

Chabaud A.G. 1975: Keys to genera of the order Spirurida. Part 1. Camallanoidea, Dracunculoidea, Gnathostomatoidea, Physalopteroidea, Rictularoidea and Thelazioidea. In: R.C. Anderson, A.G. Chabaud and S. Willmott (Eds.), CIH Keys to the Nematode Parasites of Vertebrates. No. 3. Commonwealth Agricult. Bureaux, Farnham Royal, Bucks, 27 pp.

Dewi K., Palm H.W. 2017: Philometrid nematodes (Philometridae) of marine teleosts from Balinese waters, Indonesia, including the description of Philometra damriyasai sp. nov. Zootaxa 4341: 577-584.

Froese R., Pauly D. (Eds.) 2017: FishBase. World Wide Web electronic publication, http://www.fishbase.org, 11/2017.

Gibbons L.M. 2010: Keys to the Nematode Parasites of Vertebrates. Supplementary Volume. CABI Publishing, Wallingford, $416 \mathrm{pp}$.

González-Solís D., Moravec F., Tuz Paredes V.M. 2007: A new species of Dentiphilometra (Nematoda: Philometridae) from the musculature of the gray snapper Lutjanus griseus (Osteichthyes) off the Caribbean coast of Mexico. J. Parasitol. 93: 1132-1135.

Ivashin V.M., Sobolev A.A., Khromova L.A. 1971: [Camallanata of Animals and Man and the Diseases Caused by Them.] Osnovy Nematodologii 22. Nauka, Moscow, 388 pp. (In Russian.)

Johnston T.H., Mawson P. 1940: Some nematodes parasitic in Australian freshwater fish. Trans. Roy. Soc. S. Australia 64: 340-352.

Junker K., MutafChiev Y. 2017: Micropleura huchzermeyeri n. sp. (Camallanida: Dracunculoidea: Micropleuridae) from the Nile crocodile, Crocodylus niloticus Laurenti (Reptilia: Crocodylidae), in South Africa. Syst. Parasitol. 94: 785-795.

Kardousha M.M. 1999: The first record of Philometra lateolabracis Yamaguti, 1935 (Nematoda: Spirurida; Philometridae) from teleost fishes of the Arabian Gulf. Qatar Univ. Sci. J. 18: 131-136.

Moravec F. 2001: Some helminth parasites from Morelet's crocodile, Crocodylus moreletii, from Yucatan, Mexico. Folia Parasitol. 48: 47-62.

Moravec F. 2004: Some aspects of the taxonomy and biology of dracunculoid nematodes parasitic in fishes: a review. Folia Parasitol. 51: 1-13.

Moravec F. 2006: Dracunculoid and Anguillicoloid Nematodes Parasitic in Vertebrates. Academia, Prague, 634 pp.

Moravec F., Bakenhaster M. 2010: Philometrid nematodes infecting fishes from the Everglades National Park, Florida, USA, with description of two new species. Folia Parasitol. 57: 213-222.
Moravec F., Bakenhaster M., Fajer-Ávilla E. J. 2014b: Three new gonad-infecting species of Philometra (Nematoda: Philometridae) parasitic in Lutjanus spp. (Lutjanidae) in the northern Gulf of Mexico off Florida, USA. Folia Parasitol. 61: 355-369.

MorAVEC F., BARTON D.P. 2015: Two gonad-infecting species of Philometra (Nematoda: Philometridae) from marine fishes off the northern coast of Australia. Parasite 22: 4

Moravec F., Barton D.P. 2016: New tissue-dwelling species of Philometra Costa, 1845 and Philometroides Yamaguti, 1935 (Nematoda: Philometridae) from marine perciform fishes off the northern coast of Australia. Syst. Parasitol. 93: 623-637.

Moravec F., De Buron I. 2009: Two new species of philometrids (Nematoda: Philometridae) from marine fishes off South Carolina. J. Parasitol. 95: 722-727.

Moravec F., DE Buron I. 2013: A synthesis of our current knowledge of philometrid nematodes, a group of increasingly important fish parasites. Folia Parasitol. 60: 81-101.

Moravec F., Chaabane A., Neifar L., Gey D., Justine J.-L. 2016: Descriptions of Philometra aenei n. sp. and P. tunisiensis n. sp. (Nematoda: Philometridae) from Epinephelus spp. off Tunisia confirm a high degree of host specificity of gonad-infecting species of Philometra Costa, 1845 in groupers (Serranidae). Syst. Parasitol. 93: 115-128.

Moravec F., Diggles B.K. 2014a: Two new gonad-infecting species of Philometra Costa, 1845 (Nematoda: Philometridae) from marine fishes off the northern coast of Australia. Syst. Parasitol. 89: 33-44.

Moravec F., Diggles B.K. 2014b: Philometrid nematodes (Philometridae) from marine fishes off the northern coast of Australia, including three new species. Folia Parasitol. 61: 37-54.

Moravec F., Diggles B.K. 2015: A new gonad-infecting species of Philometra, P. barnesi sp. n. (Nematoda: Philometridae), from the marine fish Pomadasys argenteus (Haemulidae) off the northern coast of Australia. Parasitol. Res. 114: 4121-4126.

Moravec F., Diggles B., Barnes L., Macbeth W. 2014a: Buckleyella ornata n. sp. (Nematoda: Philometridae) from the abdominal cavity of the talang queenfish Scomberoides commersonnianus (Perciformes: Carangidae) off the northern coast of Australia. Helminthologia 51: 230-235.

Moravec F., Justine J.-L. 2011: Two new gonad-infecting Philometra species (Nematoda: Philometridae) from the marine fish Lutjanus vitta (Perciformes: Lutjanidae) off New Caledonia. Folia Parasitol. 58: 302-310.

Moravec F., Kay W.R., HobBs R.P. 2004: Micropleura australiensis n. sp. (Nematoda: Micropleuridae) from the body cavity of Crocodylus johnsoni in Western Australia. J. Parasitol. 90: 322-326.

Moravec F., Manoharan J. 2014: Two new gonad-infecting species of Philometra (Nematoda: Philometridae) parasitic in Lutja- 
nus spp. (Osteichthyes: Lutjanidae) in the Bay of Bengal, India. Parasitol. Res. 113: 3299-3307.

Moravec F., Prouza A. 2003: New data on the morphology of two nematode species from Caiman crocodilus from Venezuela. Acta Parasitol. 48: 111-118.

Moravec F., Wang G.T. 2002: Dentiphilometra monopteri $\mathrm{n}$. gen., n. sp. (Nematoda: Philometridae) from the abdominal cavity of the ricefield eel Monopterus albus in China. J. Parasitol. 88: 961-966.
Quiazon K.M.A., Yoshinaga T., Ogawa K. 2008: Taxonomical study into two new species of Philometra (Nematoda: Philometridae) previously identified as Philometra lateolabracis (Yamaguti, 1935). Folia Parasitol. 55: 29-41.

RasheEd S. 1963: A revision of the genus Philometra Costa, 1845. J. Helminthol. 37: 89-130.

Cite this article as: Moravec F., Barton D.P. 2018: New records of philometrids (Nematoda: Philometridae) from marine fishes off Australia, including description of four new species and erection of Digitiphilometroides gen. n. Folia Parasitol. 65: 005. 